\title{
Seismic Response Analysis of Deep Underground Roadways and Coal Pillars under the Influence of the Adjacent Goaf
}

\author{
Xu Cao $(\mathbb{D}$, Xiaoshan Cao $\mathbb{D}$, and Tielin Han $(\mathbb{D}$ \\ School of Civil Engineering and Architecture, Xi'an University of Technology, Xi'an, Shaanxi, China \\ Correspondence should be addressed to Xiaoshan Cao; caoxsh@xaut.edu.cn
}

Received 12 January 2021; Revised 18 May 2021; Accepted 26 May 2021; Published 11 June 2021

Academic Editor: Guang-Liang Feng

Copyright ( $92021 \mathrm{Xu}$ Cao et al. This is an open access article distributed under the Creative Commons Attribution License, which permits unrestricted use, distribution, and reproduction in any medium, provided the original work is properly cited.

In this work, a numerical study is conducted on the seismic response of deep-buried roadways in coal mines under the influence of goafs, and a 3D numerical model of the seismic response simulation of deep-buried roadways is established using the coupling model of the finite difference method and the distinct element method. This model simulates the seismic response of different coal pillar widths and the seismic conditions of the deep-buried roadways under the influence of the adjacent goafs. The deformation, stress distribution, and plastic area distribution of roadways and coal pillars are systematically studied, and the situations under the static load and the roadways, which are not affected by the goafs, are compared and analyzed. A reasonable width of the coal pillar is proposed on the basis of the stability of the roadway and the coal pillars. In the end, suggestions for the reasonable setting of coal pillars under seismic load are provided.

\section{Introduction}

The earthquake disaster causes serious damage to ground buildings and brings about serious effects to underground structures $[1-3]$. The deep underground mining often induces seismic activity, which is called mine earthquake [4-7]. Natural and mine earthquakes are not essentially different $[8,9]$. Natural earthquakes have caused different degrees of damage to coal mines $[10,11]$. Underground coal mines are gradually affected by mine earthquakes with increased coal mining depth $[12,13]$. In the limited deep space, mine earthquakes may cause a series of other coal mine disasters, such as rock explosion, coal and gas outburst [14], and water penetration [15-20]. Therefore, the response of deep underground coal mine structure should be analyzed under the seismic load.

The gob-side entry driving is a long-walled coal mining often used in the form of exploitation [21-25], and the roadway driving with coal pillars can effectively isolate the goaf to prevent water and harmful gases in the goafs into the roadway [26, 27]. Feng et al. [28] established the relationship between microseismicity and the risk of rockburst and then proposed an early warning technique based on it to predict the rockburst in tunnels. By analyzing the monitored microseismic data, this method can provide a real-time early warning of the rockburst risk during excavation of the tunnel. The application of this method in some engineering cases shows that it can well predict the development of rock burst $[29,30]$. $\mathrm{Li}$ and Chai [31] studied the relationship between the width of coal pillars and the susceptible coal explosion in deep-buried roadways and proposed a reasonable coal pillar width setting to reduce the risk of the coal explosion. Considering that coal pillars play a supporting role in the active coal mining space and are subjected to different forms of dynamic action, the current mining stress of the coal mining face is the main dynamic form. Coal pillars are also affected by the process of isolating the goaf and the overlying rock strata sinking the goaf during the compaction process. Coal pillars are affected by dynamics, which often cause large deformations and bring about difficulties to the coal mining. Zhao et al. [32] and Wang et al. [33] analyzed the stress changes and the damage risks of coal pillars under dynamic and static loads with specific cases and proposed reasonable coal pillars under corresponding geological conditions. In previous studies, underground chambers or roadways often produced a certain 
amount of deformation under the action of earthquake loads. Wang et al. [34] analyzed the seismic response of underground gas storage salt caverns, which produce certain deformation and damage in the seismic response. In turn, the seismic response has a certain effect on the safety of gas storage salt caverns. This deformation does not pose a great threat to the roadway in the coal mining space of the coal mine, and the effect of the dynamic stress on the roadway far from the goaf is small [35-37]. However, the deformation of the roadway formed by the gob-side entry driving due to the isolation of coal pillars near the goaf is often severe. In the study of the dynamic response of isolated coal pillars under the action of the goaf, the goaf is often regarded as a continuous medium [38-40], which is often inconsistent with the actual situation of broken rocks in the adjacent goaf.

In this study, the finite difference method (FDM) and the distinct element method (DEM) are coupled, and a continuous medium model of isolated coal pillars and formations is established. A discrete medium model of the adjacent goaf is established using the DEM. The effect of the adjacent goaf under seismic load on the coal pillar and the response of coal pillars with different widths under the seismic load are analyzed. These results should provide suggestions for the reasonable setting of coal pillars under the seismic load.

\section{FDM and DEM Constitutive Models}

The computational resource required to model coal strata sequence using a distinct element code similar to PFC is enormous, especially in dynamic calculation. The goaf is filled with broken gangue, and the discrete medium in the goaf belongs to unbonded granular materials. Therefore, using PFC to simulate the goaf is reasonable. The MohrCoulomb model is widely used in the seismic analysis in the nonlinear dynamic analysis in geotechnical engineering [41-43]. The continuum model is selected for the coal pillar and the adjacent complete stratum, and the Mohr-Coulomb model is selected for the constitutive relationship of the model. The contact connection model is used to simulate the discrete medium in the goaf without considering the internal fragmentation of the particles. The solid element (zone) in the FDM and the wall in the DEM are used for coupling. The coupling of FDM and DEM is required to reduce computation time while ensuring solution accuracy.

A model (Figure 1) is established to verify the feasibility of the coupling scheme. The length, width, and height dimensions of the overall model are $160 \mathrm{~m} \times 5 \mathrm{~m} \times 15 \mathrm{~m}$ in the $x, y$, and $z$ directions in the software. The hollow area of $150 \mathrm{~m} \times 5 \mathrm{~m} \times 10 \mathrm{~m}$ is filled with the DEM and the FDM. The mechanical parameters related to the FDM and the DEM are shown in Table 1. FDM parameters are obtained from coal mine strata. The DEM refers to the data in literature [44]. In the coupling model of the FDM and the DEM, the DEM particle size is $0.2-0.5 \mathrm{~m}$. A total of 24,816 particles (balls) are generated, and the number of physical units (zone) is 4,500 . The number of solid elements (zone) is 12,000 in the model with only continuum.

After the model is established, the parameters are assigned, and the bottom and all sides of the model are fixed.

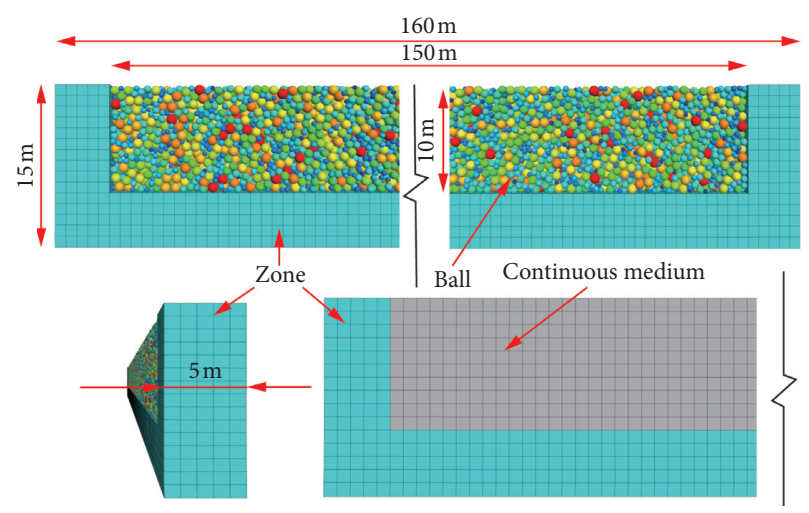

FIgURE 1: Coupling verification model.

No stress or restriction is observed in the upper part. The self-weight stress balance is calculated, and the model displacement and the velocity are initialized to 0 . The acceleration time range (Figure 2) is entered from the bottom of the model and provides artificial waves for the software. The acceleration equation for the wave is

$$
u(t)=\frac{1}{2}\left(1-\cos \left(\frac{\pi}{3} t\right)\right) A \sin (2 \pi f t),
$$

where $A$ is the amplitude and $f$ is the frequency.

The free-field boundary is applied around the model to reduce the reflection of the acceleration wave. The static boundary conditions are removed, and the dynamic response of the model is verified under the influence of no surrounding stress. The dimensional effects are considered. The distance at the $y$ direction is short, and the free-field boundary is observed at both ends. The acceleration in the $y$ direction is set to 0 , and the acceleration in the $x$ and $z$ directions is entered in accordance with the actual size.

The model dynamic calculation time is set to $10 \mathrm{~s}$. The coupling of FDM and DEM under self-weight stress (Figures 3(a) and 3(b)) and dynamic load (Figures 3(c) and $3(d))$ conditions and the vertical stress in the left pillar of the continuous medium models (Figures 3(b) and 3(d)) is extracted to verify that the response of the bulk and the continuum media to the cylinder differs. The coordinates of the pillars are $x(0-5), y(0-5)$, and $z(0-15)$, and the stress is extracted from $x=4.9$ in the $x$ plane. Considering that 5.0 is affected by displacement, some areas cannot be extracted due to stress. As shown in Figure 3, the vertical stress of the continuum (Figure 3(b)) shows a linear change along the $z$ axis as a whole under the condition of self-weight stress. However, the coupling model of the FDM and the DEM (Figure 3(a)) is affected by the contact stress of the loose body. Moreover, the local area is no longer linear, shows a fluctuation in the whole plane, and does not change uniformly in the direction of the $y$-axis. These observations show that the DEM and the continuum have completely different forces on adjacent areas. This difference is also evident under the dynamic load conditions. As shown in Figures 3(c) and 3(d), the stress distribution in the continuous medium (Figure 3(d)) shows a certain regularity. For example, at the position of $z=0$, the vertical stress in the 
TABLE 1: Reference table of FDM and DEM physical mechanical parameters.

\begin{tabular}{lccccc}
\hline $\begin{array}{l}\text { Name of coal } \\
\text { and rock mass }\end{array}$ & Bulk modulus $(\mathrm{GPa})$ & Shear modulus $(\mathrm{GPa})$ & Density $\left(\mathrm{kg} / \mathrm{m}^{3}\right)$ & Cohesion $(\mathrm{MPa})$ & Internal friction angle $\left(^{\circ}\right)$ \\
\hline Model floor, $5 \mathrm{~m}$ & 5.9 & 2.5 & 2620 & 1.3 & 29 \\
Left and right pillars & 3.1 & 1.5 & 1420 & 0.5 & 22 \\
\hline \multicolumn{5}{c}{ Mechanical parameters in the DEM model } \\
Contact modulus $E_{c}$ & Stiffness ratio & Frictional & Normal strength $/ \sigma_{c}$ & Tangential strength $/ \tau_{c}$ \\
$(\mathrm{GPa})$ & $k_{n} / k_{s}$ & coefficient $\mu$ & $(\mathrm{MPa})$ & $(\mathrm{MPa})$ \\
10 & 1.0 & 0.5 & 10 & 10 \\
\hline
\end{tabular}

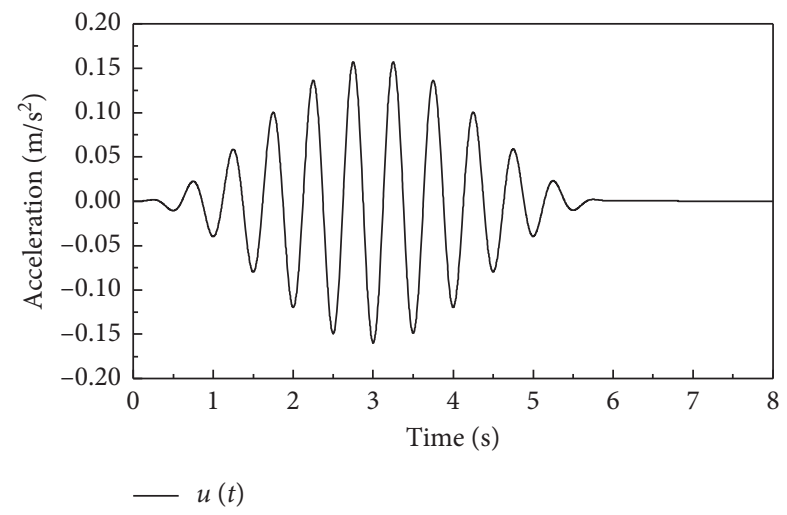

FIgURE 2: Input acceleration time history.

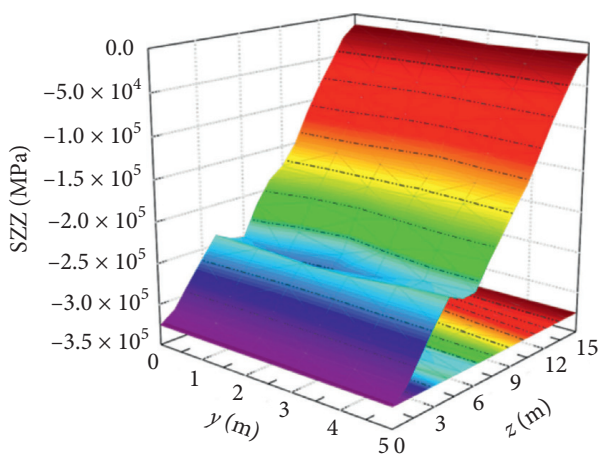

(a)

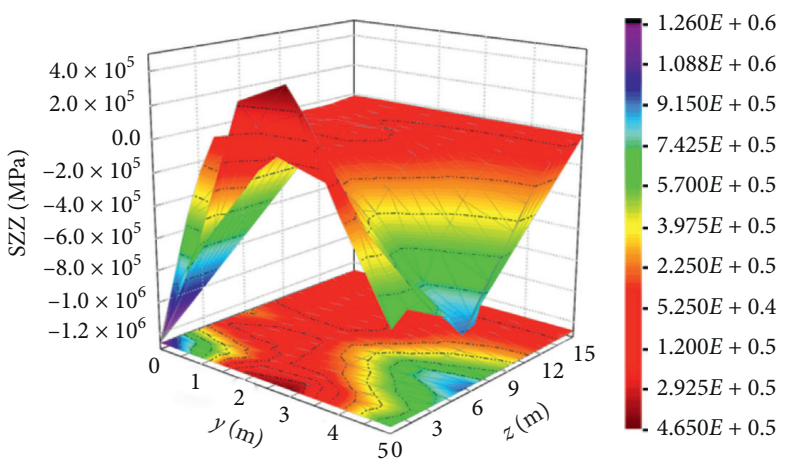

(c)

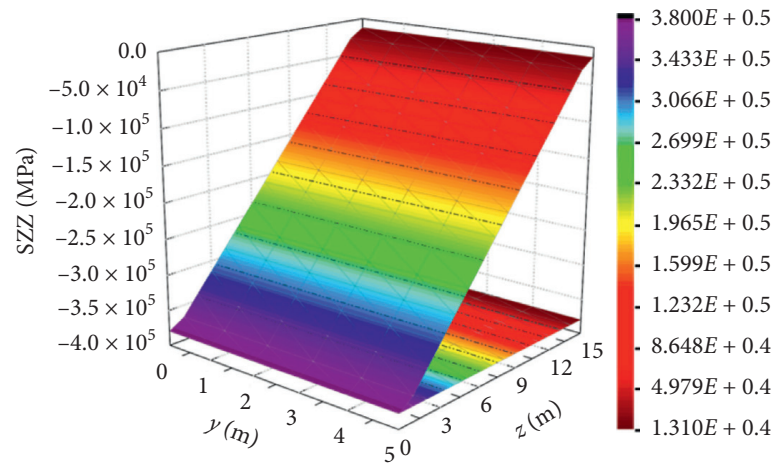

(b)

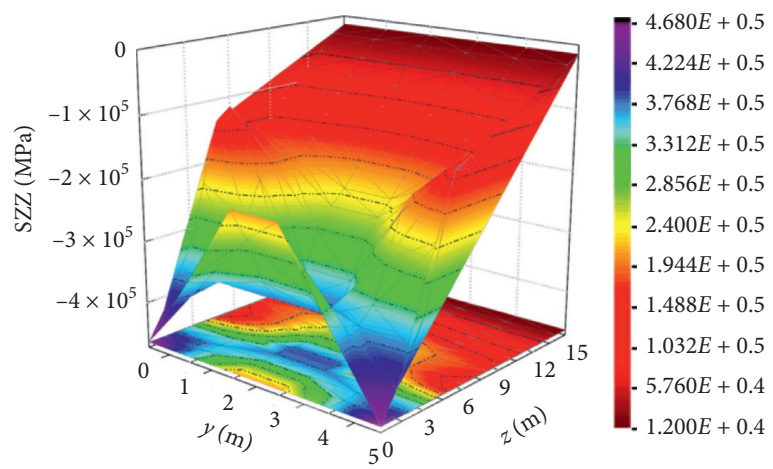

(d)

Figure 3: Vertical stress distribution of the left column under the self-weight and the dynamic load.

$y$ direction is low at both ends, high in the middle, linear, and gradually stable from both ends to the middle. At the position of $y=2.5$, the stress in the $z$ direction increases first and then decreases. In the FDM and the DEM coupling model (Figure 3(c)), an irregularity between the self-weight stress and the continuous medium is observed. Therefore, 
the dynamic load response of coal pillars under this discrete medium, which is different from the continuous medium, should be studied.

\section{Establishment of the Numerical Model}

3.1. Geological Background and Site Details. The Kongzhuang Coal Mine in Xuzhou, China, was selected as a numerical example. The longwall panels (7433 panels and 7435 panels) with width of $200 \mathrm{~m}$ and length of $100 \mathrm{~m}$ are selected. The coal seam thickness of the working face is $4.20 \mathrm{~m} \sim 5.10 \mathrm{~m}$, and the average thickness is $4.60 \mathrm{~m}$.

The immediate roof of the coal seam is sandy mudstone, with a thickness of $0.60 \sim 11.19 \mathrm{~m}$, an average thickness of $3.90 \mathrm{~m}$, gray-black, thin-layered, uneven sand content, and more plant fossils. The main roof is composed of siltstone and medium-grained sandstone. The thickness of siltstone is $1.87 \sim 3.21 \mathrm{~m}$ with an average thickness of $1.50 \mathrm{~m}$. The thickness of medium-grained sandstone is $5.23 \sim 9.81 \mathrm{~m}$ with an average thickness of $6.66 \mathrm{~m}$. The siltstone is gray-white; the main components are quartz, feldspar, calcareous cement, compact, fine-grained sand-like structure, and nearly horizontal bedding; for details, see Figure 4 .

3.2. Modeling and Solutions. The numerical model is established on the basis of the tail entry of the 7435 working face of the Kongzhuang Coal Mine. The 7435 working face is the first working face buried more than $1000 \mathrm{~m}$ deep in Kongzhuang Coal Mine. The plane relationship between 7433 and 7435 working faces is shown in Figure 5. During mining at the 7433 working face, if the 7435 working face is excavated, then an isolated coal pillar should be set between two working faces. The length along the dip of the two working faces is $150 \mathrm{~m}$. Thus, the length along the dip of the 7433 goaf is $150 \mathrm{~m}$, and the tail entry of the 7435 working face is shown in Figure 5. The width and the height of the roadway section are 5 and $4 \mathrm{~m}$, respectively. The 3D sizes of the comprehensive strata histogram and model are shown in Figure 4 . The size of the model in the $x$ direction is $350 \mathrm{~m}$, and the sizes in the $z$ and $y$ directions are 200 and $5 \mathrm{~m}$, respectively. The layout of monitoring points around the roadway is shown in Figure 4 to monitor the displacement and the stress of the roadway and the coal pillars. The height dimension of the goaf, that is, the caving zone, uses statistical theoretical analysis to arrive at the regression formula of the fall zone on the basis of the highly measured data of the caving zone of a large number of goafs in China and the United States made by Bai et al. [45].

$$
H_{c}=\frac{100 h}{c_{1} h+c_{2}},
$$

where $H_{c}$ is the height of the caving zone $(\mathrm{m}), h$ is the height mining $(\mathrm{m})$, and $c_{1}$ and $c_{2}$ are the strata strength parameters. The values of $c_{1}$ and $c_{2}$ can be determined on the basis of literature [45]. The 7433 working face has a mining height of $4.5 \mathrm{~m}$, and the calculated caving zone height is approximately $11.2 \mathrm{~m}$ and is regarded as $11 \mathrm{~m}$. The working face has a length of $150 \mathrm{~m}$. Therefore, the size of the goaf is (i)
$X \times Y \times Z, 150 \mathrm{~m} \times 5 \mathrm{~m} \times 11 \mathrm{~m}$ by using the DEM for modeling. The DEM model (Figure 6) is built. The randomly generated geometric model is imported from the external software to simulate the broken rocks in the goaf realistically, and the spherical particles are filled into the geometric model to make the surface of the model as close to the actual one as possible under stable model conditions. For the physical and mechanical parameters of the two models, the FDM parameters are determined in accordance with the geological conditions of field engineering and the mechanical properties of the rock formations. The DEM model parameters are determined in reference to literature [44], and the physical mechanical parameters are presented in Table 2.

The total numbers of model units and DEM are 124250 and 3866, respectively. The size of broken rock mass is $0.3-2 \mathrm{~m}$, and the particles of the broken rock mass are randomly generated in this range. The porosity of the model is 0.3 . In this discussion, the effect of particle breakage and size is ignored. The position of the 7435 tail entry in the model moves to the left in the dashed box of Figure 4 to change the widths of the coal pillar to $5,7,9,11,13,15,20$, $25,30,35$, and $40 \mathrm{~m}$, which indicates the construction of 11 models. The grid size of the model is dense around the adjacent roadway and the goaf. The grid size is far from the roadway, and the goaf is appropriately enlarged to improve the accuracy of the calculation without affecting the calculation results.

The 7435 working face of the Kongzhuang Coal Mine has an elevation of $-1017.50 \mathrm{~m}$ to $-883.80 \mathrm{~m}$. This study ignores the effects of the stratigraphic dip. The working face is arranged horizontally. The working face and the roadway are arranged at $1000 \mathrm{~m}$. The rock mass density and the upper vertical stress are valued at $2500 \mathrm{~kg} / \mathrm{m}^{3}$ and $25 \mathrm{MPa}$, respectively, and the horizontal stress ratio is 1.5 during the static calculation of the model. The front, rear left, right, and the bottom are fixed at the model static calculation boundary conditions. The dynamic boundary condition of the model is the free-field boundary condition to reduce the reflection of waves.

The mechanical parameters of coal and rock can be found in Table 2, and the DEM mechanical parameters are the same as those in Table 1. The two sides of the 7435 return airway are supported by bolts, with length, diameter, and spacing of $2.4 \mathrm{~m}, 20 \mathrm{~mm}$, and $1 \mathrm{~m} \times 1 \mathrm{~m}$, respectively. Four anchors are present on each section with the yield load and pretightening force of 150 and $80 \mathrm{kN}$, respectively. The roof is supported by bolts and cables with spacing of $1 \mathrm{~m} \times 1 \mathrm{~m}$. The anchor cables are arranged in the middle of the bolts near the middle point of the bolster and the roof of the roadway with anchor cable diameter, length, yield load, and pretightening force of $17.8 \mathrm{~mm}, 8.2,600 \mathrm{kN}$, and $150 \mathrm{kN}$, respectively.

3.3. Input and Processing of Seismic Waves. In the calculation process, the Northridge, Loma, Kobe, and artificial seismic waves are used [46]. The first 20 of the four seismic waves are extracted as input dynamic loads, and the four seismic waves 


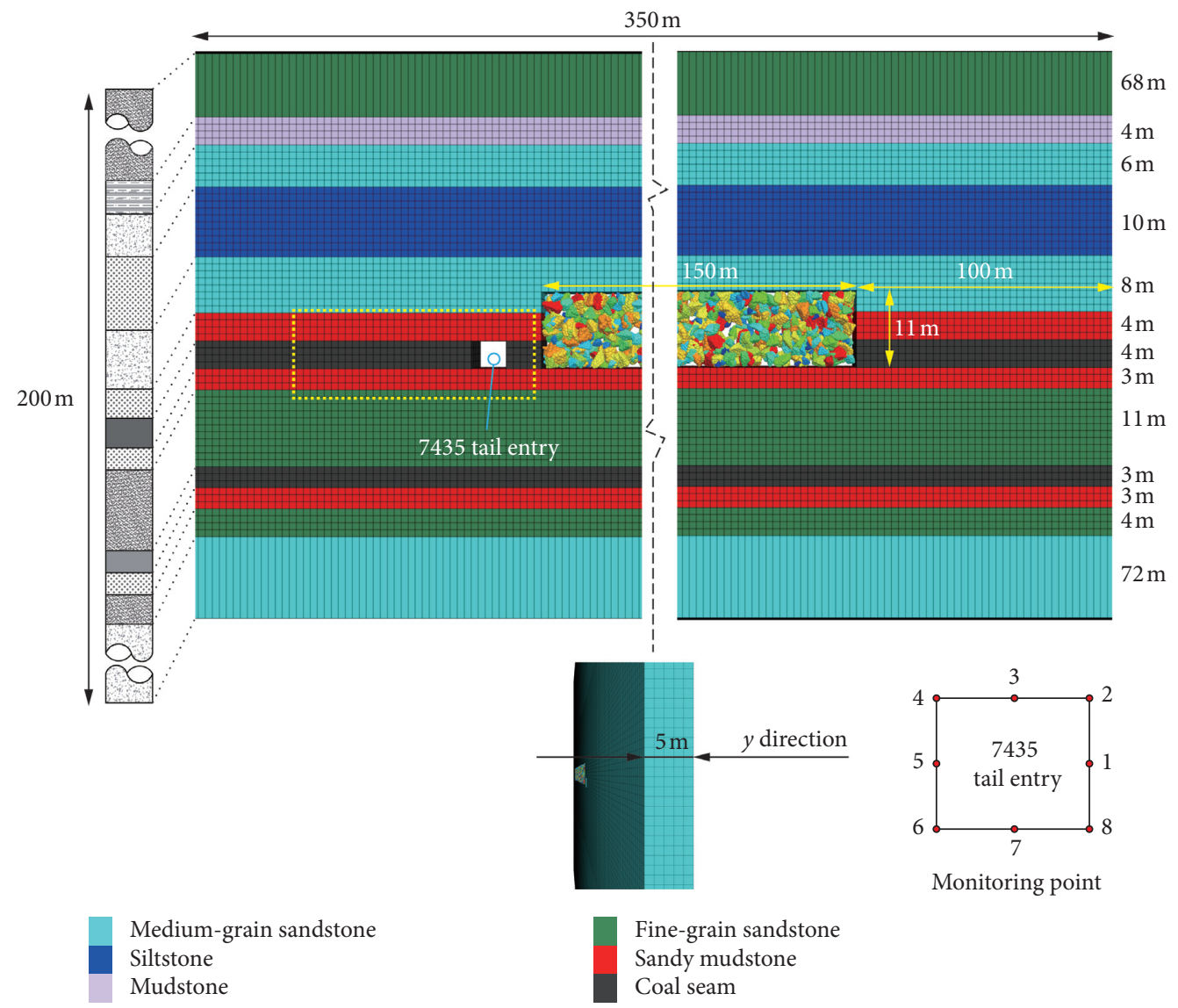

Figure 4: 3D size of the numerical model and integrated stratigraphic histogram.

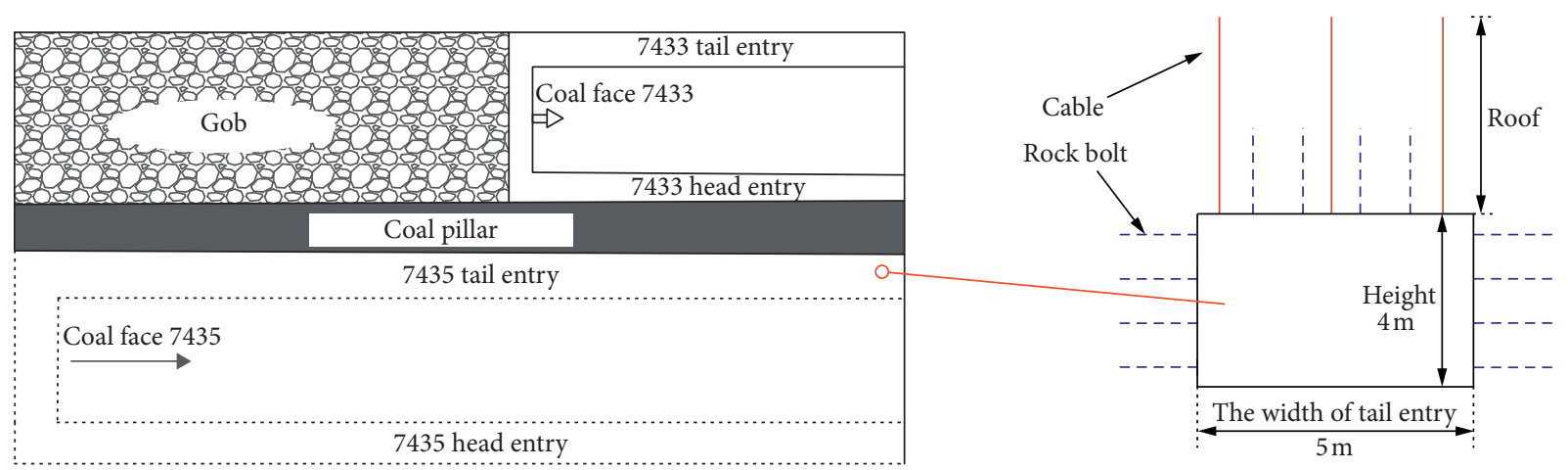

FIGURE 5: Plane position relationship of the model and the support form of the 7435 return airway.

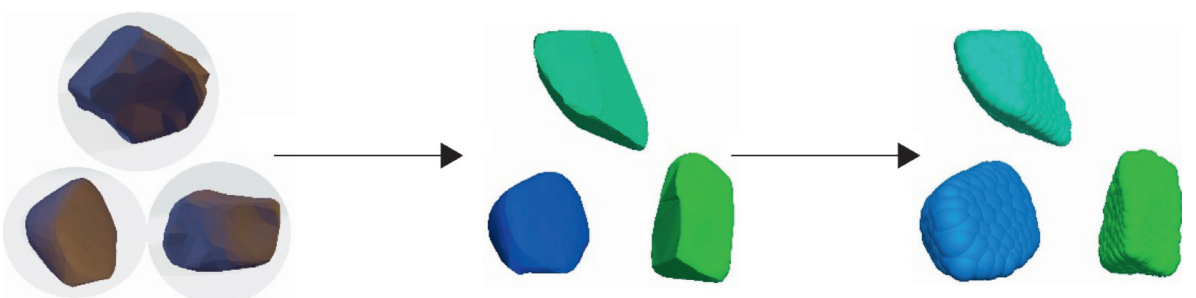

FIGURE 6: Establishment of the DEM model. 
TABLe 2: Physical and mechanical parameters used in the model.

\begin{tabular}{|c|c|c|c|c|c|}
\hline Name of coal and rock mass & Bulk modulus (GPa) & Shear modulus $(\mathrm{GPa})$ & Density $\left(\mathrm{kg} / \mathrm{m}^{3}\right)$ & Cohesion $(\mathrm{MPa})$ & Internal friction angle $\left({ }^{\circ}\right)$ \\
\hline Siltstone & 9.1 & 3.8 & 2500 & 16 & 37 \\
\hline Mudstone & 6.6 & 2.2 & 2550 & 10 & 35 \\
\hline Fine sandstone & 9.2 & 4.0 & 2700 & 20 & 43 \\
\hline Coal & 3.1 & 1.5 & 1420 & 5 & 22 \\
\hline SDSH & 5.9 & 2.5 & 2620 & 13 & 29 \\
\hline Medium-grain sandstone & 8.7 & 4.1 & 2500 & 18 & 40 \\
\hline
\end{tabular}

are filtered and baseline-corrected using the SeismoSignal [47] software. This procedure eliminates a small number of high-frequency waves in the seismic waves, reduces the number of meshes, and ensures that the displacement and velocity of the model grid points after the power calculation are 0 . The acceleration of the four seismic waves is shown in Figures 7(a)-7(d). Considering the effect of the model size, the acceleration of the seismic wave in the $y$ direction is set to 0 due to the small size of the $y$ direction, and the acceleration in the $x$ and $z$ directions is entered in accordance with the original size.

\section{Deformation Characteristics of Roadway}

4.1. Horizontal Deformation. Figure 8 shows a change curve in the horizontal displacement of 56 study cases, including 11 different coal pillar widths under static load conditions and four seismic wave conditions. Figures 8(a), 8(c), 8(e), $8(\mathrm{~g})$, and $8(\mathrm{~h})$ show the horizontal displacement of monitoring point 1 , which reveals the maximum horizontal displacement change on the side of the coal pillar of the roadway. Figures $8(\mathrm{~b}), 8(\mathrm{~d}), 8(\mathrm{f}), 8(\mathrm{~h})$, and $8(\mathrm{j})$ show the horizontal displacement of monitoring point 5 , which reveals the maximum horizontal displacement change curve of the solid coal side of the 7435 return air lane, where a and b are the horizontal displacement curves under the static load.

(1) Under the static load, the influence of width is not great within the range of 5-15 $\mathrm{m}$, and the coal pillar side of roadway total of horizontal displacement is between 0.4 and $0.5 \mathrm{~m}$. The horizontal displacement of the coal pillar with width of $5 \mathrm{~m}$ is smaller than that of the coal pillar with width of 7-15 m, and this finding is similar to that observed in previous research. The displacement change in the solid coal side of roadway between 5 and $15 \mathrm{~m}$ has also a minimal effect, that is, $0.2-0.3 \mathrm{~m}$. However, the effect on the roadway deformation is small under the coal column width of 5-9 m. Therefore, in recent years, the narrow coal roadway has been chosen to improve the coal extraction rate. The stability of the roadway and coal pillars can be maintained and the coal output can be improved under the condition of improving and strengthening the support.

(2) Within the coal pillar width range of $15-40 \mathrm{~m}$, the coal pillar side of roadway total of horizontal displacement gradually decreases with the increase in coal pillar width. The overall displacement is less than $0.3 \mathrm{~m}$. In particular, the deformation of coal pillar side of roadway reduced to $0.2 \mathrm{~m}$ when the width of coal pillar was greater than $25 \mathrm{~m}$.

(3) For the seismic reaction of a single roadway not affected by the goaf, the displacement curve is represented by no gob in Figure 8 for comparative analysis. As shown in Figure 8, the horizontal displacement change of the single-roadway deep underground, which is relatively safe for coal mining, is not affected by the goaf. This finding has also been confirmed by previous studies and surveys. However, the horizontal displacement deformations of coal pillars and roadways in adjacent goafs under the influence of frequent or continuous dynamic loads differ, and the width of the coal pillars remarkably affects the changes in displacement. Figures 8(c), $8(\mathrm{e}), 8(\mathrm{~g})$, and $8(\mathrm{i})$ represent the deformation of the coal pillar side of the roadway under the influence of four kinds of seismic waves. At the beginning of the ground motion, the displacement under the $5-15 \mathrm{~m}$ wide coal pillars increases significantly, and the displacement under the $5 \mathrm{~m}$ wide coal pillars increases to more than $0.3 \mathrm{~m}$ within $1 \mathrm{~s}$ of the ground motion. The difference from the static load condition is that the displacement under the coal pillar with width of $5 \mathrm{~m}$ no longer shows an insignificant change from that under the coal pillars with width of 7-15 $\mathrm{m}$ but continues to increase as the earthquake time continues. Under the coal pillar with width of $7-15 \mathrm{~m}$, the displacement is less than that of the coal pillar with width of $5 \mathrm{~m}$, but the effect is insignificant. When the width of the coal pillars reaches $20 \mathrm{~m}$, the trend of the lane displacement change in the preseismic period is approximately linear and gradually slows down. Figures $8(\mathrm{~d}), 8(\mathrm{f}), 8(\mathrm{~h})$, and $8(\mathrm{j})$ show the displacement curves of the solid coal side of the roadway. Considering the long distance from the goaf and the support of solid coal, the displacement is smaller than the deformation of the coal pillar side, and the overall trend of the displacement is similar to that of the solid coal side. Similarly, the displacement changes in coal pillars with width of 5-15 $\mathrm{m}$ are evident, and the coal pillars are gradually eased when their width reaches $20 \mathrm{~m}$.

(4) Different displacements are observed under four seismic conditions. The displacement under the Loma seismic wave is the largest. The maximum 


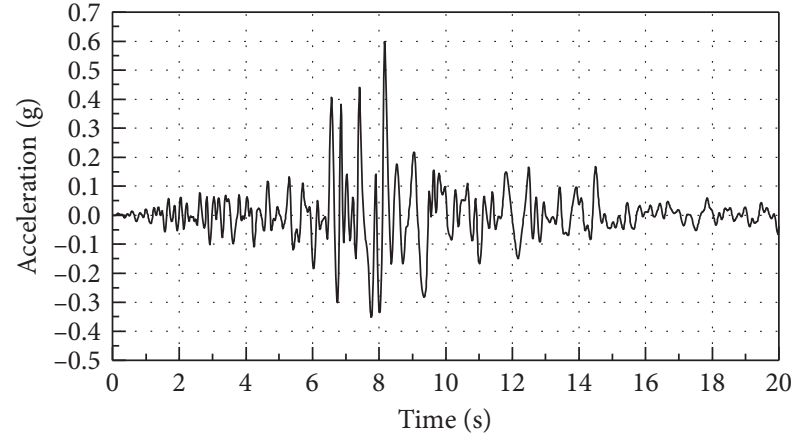

_ Northridge seismic wave

(a)

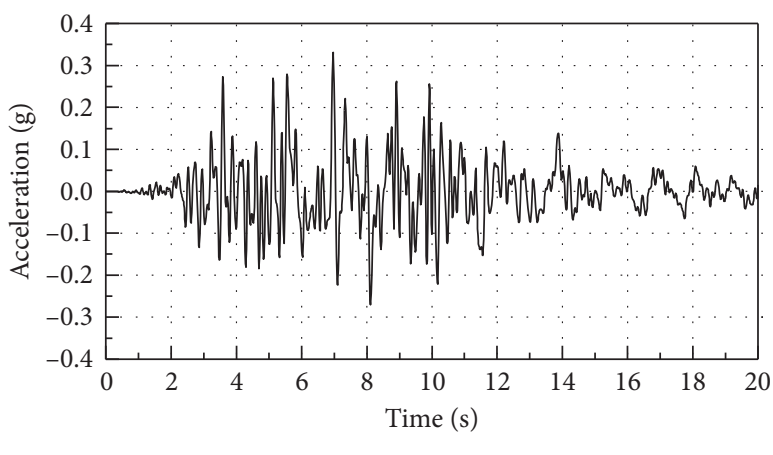

_ Kobe seismic wave

(c)

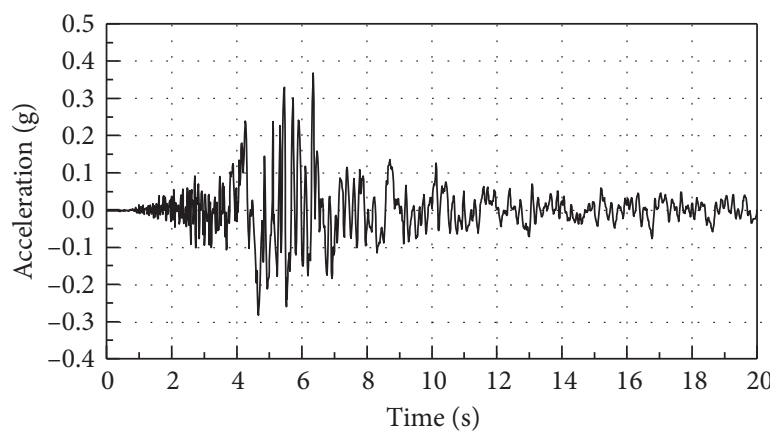

__ Loma_Prieta seismic wave

(b)

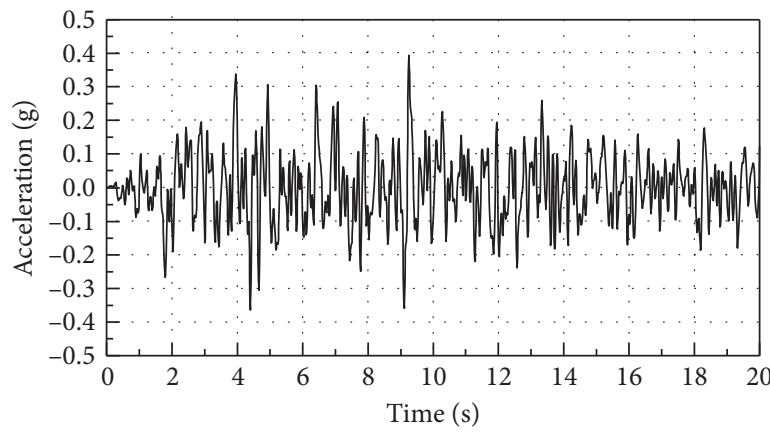

__ Artificial seismic wave

(d)

Figure 7: Acceleration records used in the filtered and corrected analysis. (a) Northridge seismic wave. (b) Loma seismic wave. (c) Kobe seismic wave. (d) Artificial seismic wave.

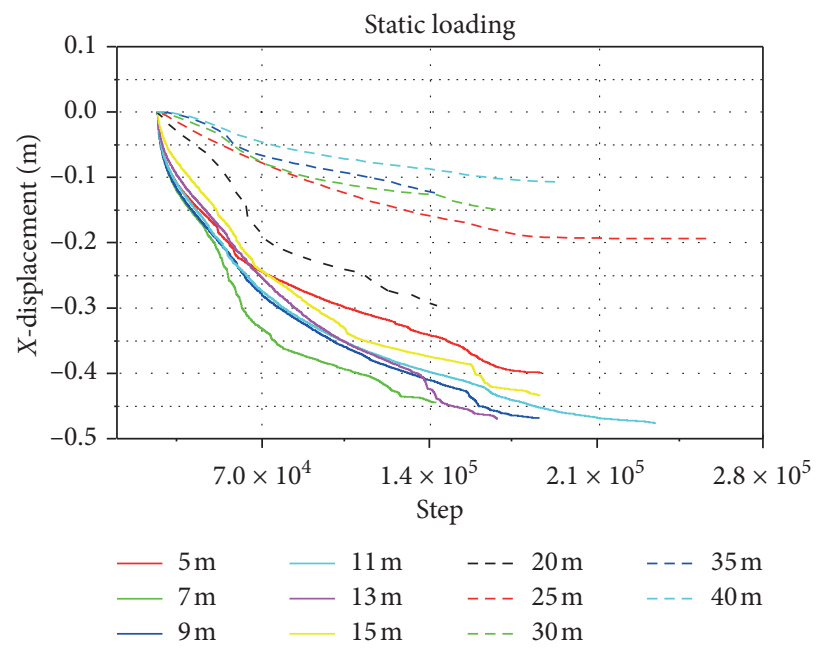

(a)

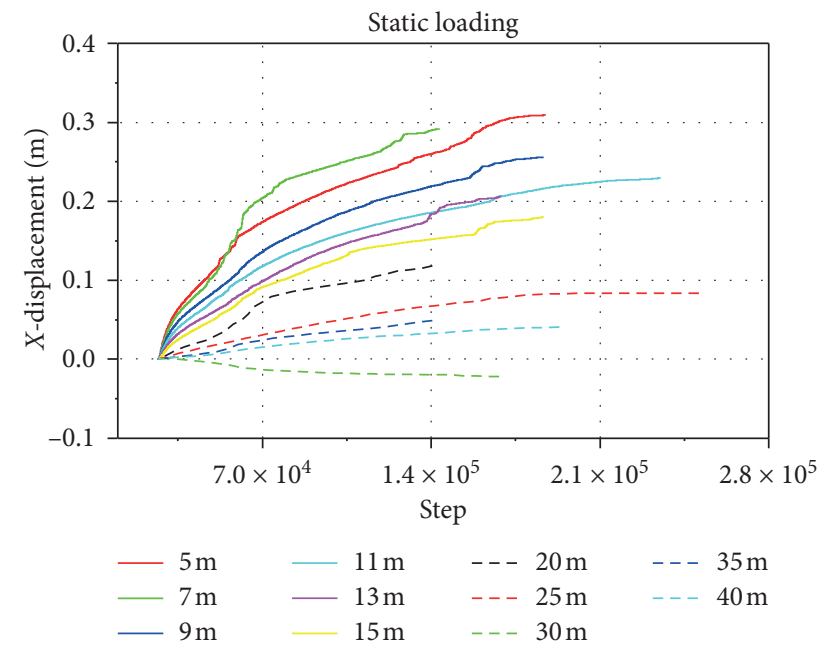

(b)

FIgURE 8: Continued. 


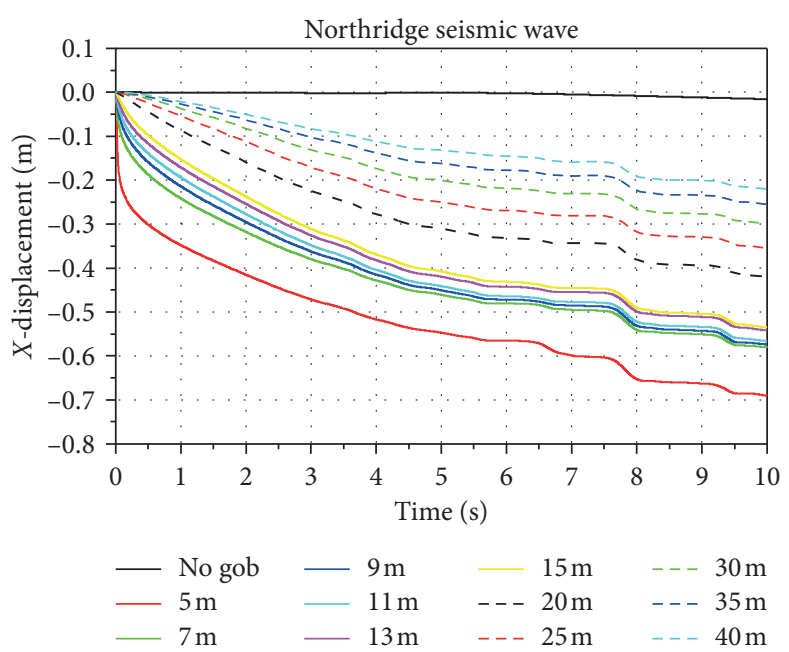

(c)
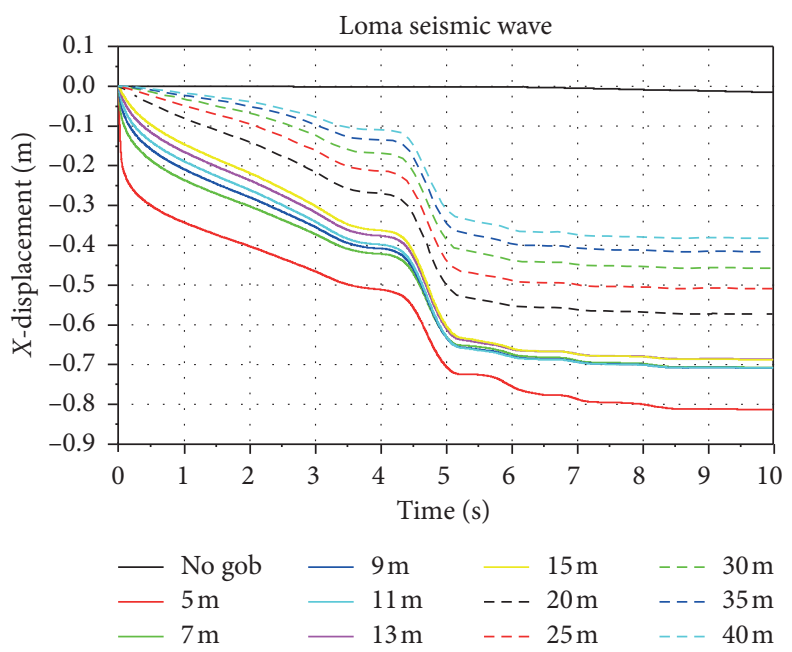

(e)
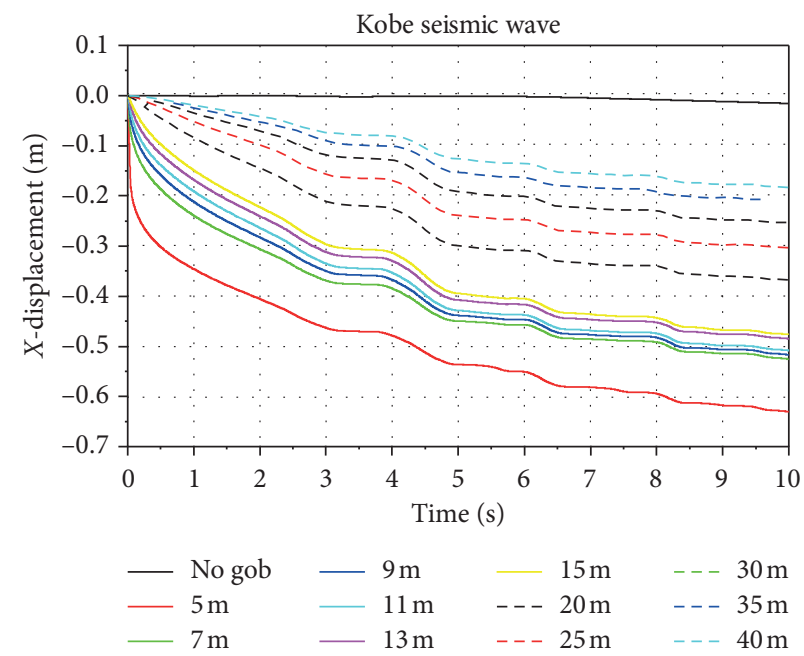

(g)

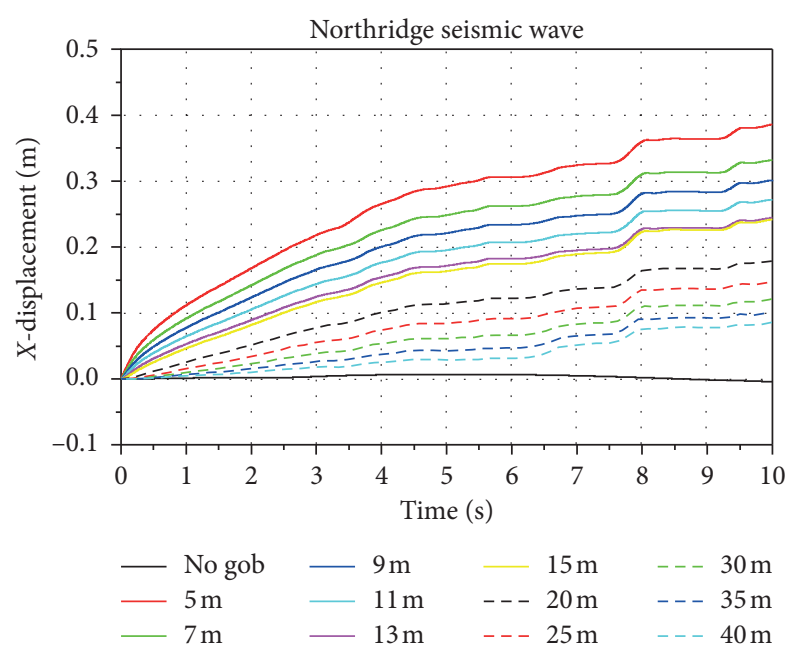

(d)

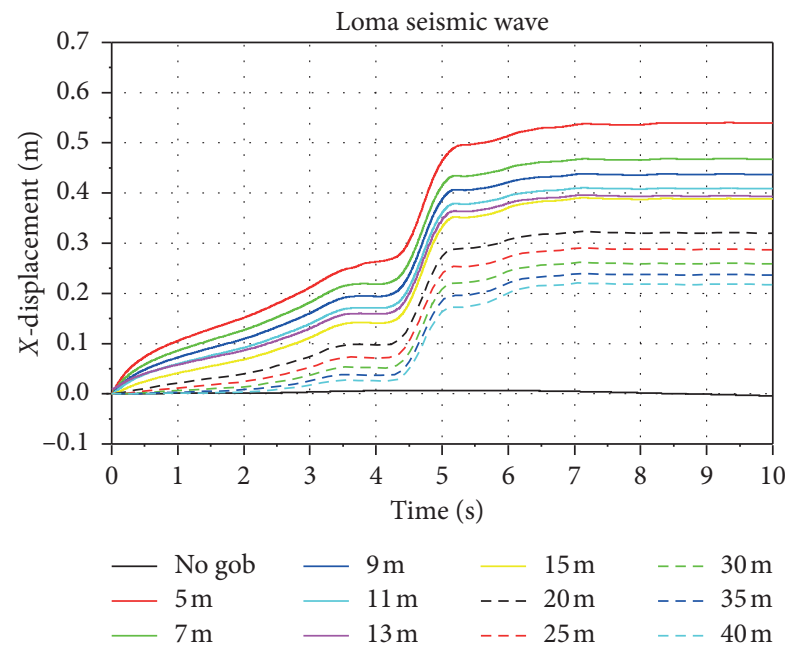

(f)
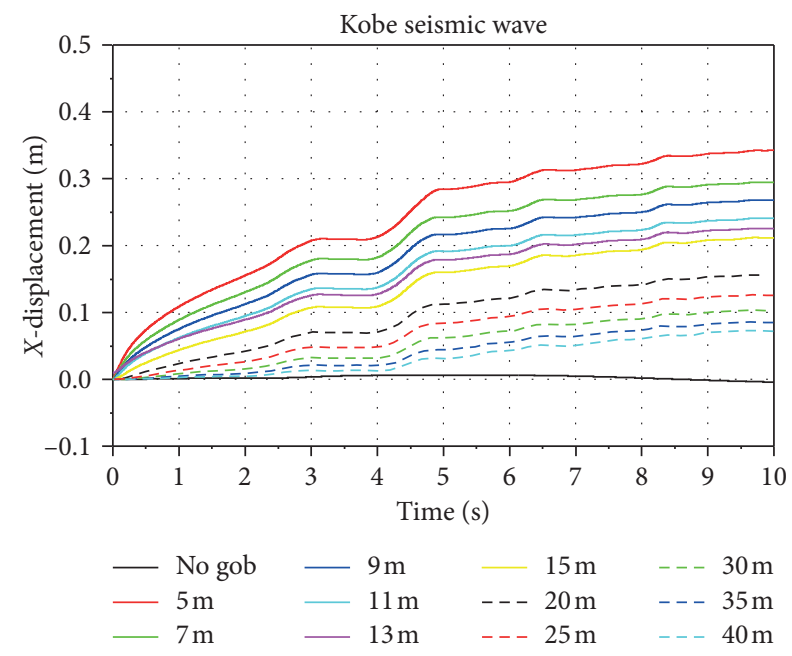

(h)

FIgure 8: Continued. 


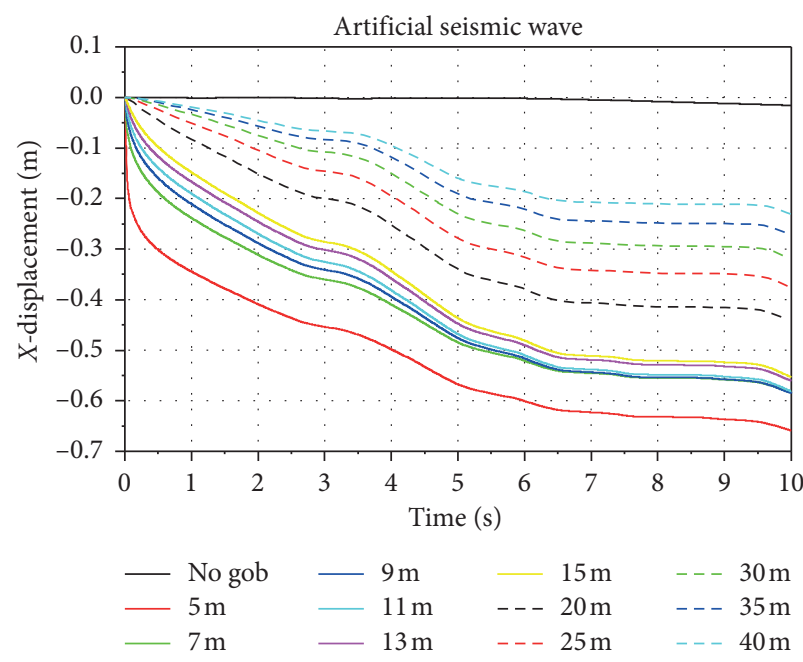

(i)

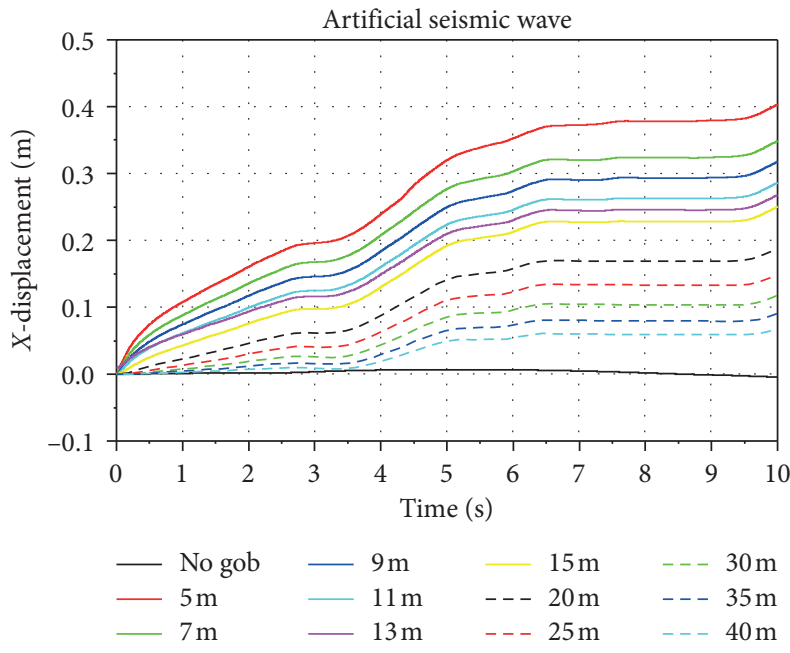

(j)

FIGURE 8: Horizontal displacement curve of monitoring points: (a, c, e, g, i) horizontal displacement of monitoring point 1, m, and (b, d, f, h, j) horizontal displacement of monitoring point $5, \mathrm{~m}$.

displacement of the coal pillar side reaches $0.81 \mathrm{~m}$ at the width of $5 \mathrm{~m}$, and the maximum displacement of the solid coal side reaches $0.54 \mathrm{~m}$. The amount of continuous displacement continues to increase with the seismic motions. Therefore, setting the width of the coal pillar to $20 \mathrm{~m}$ or greater is appropriate for the risk of instability in accordance with the narrow coal pillar design in the adjacent goafs under the influence of frequent or sustained dynamic load.

4.2. Vertical Deformation. Figure 9 shows the vertical displacement change curve of monitoring points 3 and 7 , which is the largest displacement change of all monitoring points:

(1) Figures 9(a) and 9(b) show the lane roof and floor displacement curves, respectively, under static load. The displacement of the roof under the static load is between 5 and $15 \mathrm{~m}$ coal pillar width, and the sinking volume is between 0.225 and $0.3 \mathrm{~m}$. The effect of changing the coal pillar width within this width interval on the roof sinking is insignificant. The displacement of the floor under the static load is small in coal pillars with width of 5-40 $\mathrm{m}$, and the total displacement of the floor is between -0.03 and $0.03 \mathrm{~m}$. Therefore, the effect of static load on the displacement of the floor is less under such geological conditions.

(2) Figures 9(c)-9(j) show that the displacements of the roof of the roadway and the floor under the condition of four seismic waves are the displacement curves of the floor. Similarly, no gob is the displacement response of a single roadway under the influence of no goaf. The research shows that the displacement of the roof of the roadway not affected by the goafs is small, and the roadway is relatively safe. The displacement change of the roof is influenced by the displacement of the goafs, and the general change trend of displacement increases slowly as the seismic time progresses. The maximum displacement of the coal pillar is $5 \mathrm{~m}$ wide under the Northridge and the Loma seismic waves, and the maximum roof sinking volume is close to $0.4 \mathrm{~m}$. At coal pillar width of 5-15 m, increasing the width of coal pillar only slightly reduces the amount of deformation. The displacement of the floor is accompanied by the continuous seismic movement, which shows a trend of fluctuation. The final displacement is smaller than the displacement of the roof, and the displacement of the floor is relatively safe for the stability of the roadway. Therefore, setting the width of the coal pillar to approximately $20 \mathrm{~m}$ or more under frequent or continuous dynamic conditions is reasonable in accordance with the displacement change of the top and the floors.

\section{Stress Analysis}

Figures 10 and 11 show the maximum main stress wave cloud diagrams of the roadway and coal pillars under the static load and Northridge seismic waves. More models of four seismic waves exist, and only the Northridge seismic wave is selected for comparative analysis because of space limitation. As shown in Figures 10 and 11, a low stress zone is formed around the roadway under static and dynamic conditions, and this result is due to the deformation of the excavated chamber to unload the pressure. These findings are similar to those of previous studies.

Under the static load, the stress concentration in coal pillars with width of 5 and $7 \mathrm{~m}$ is low. This case is conducive to the stability of the coal pillars. When the width is increased from $9 \mathrm{~m}$ to $20 \mathrm{~m}$, the stress concentration in the coal pillar gradually increases. The stress value gradually increases from $-10 \mathrm{MPa}$ at $9 \mathrm{~m}$ coal column to $-35 \mathrm{MPa}$ when 

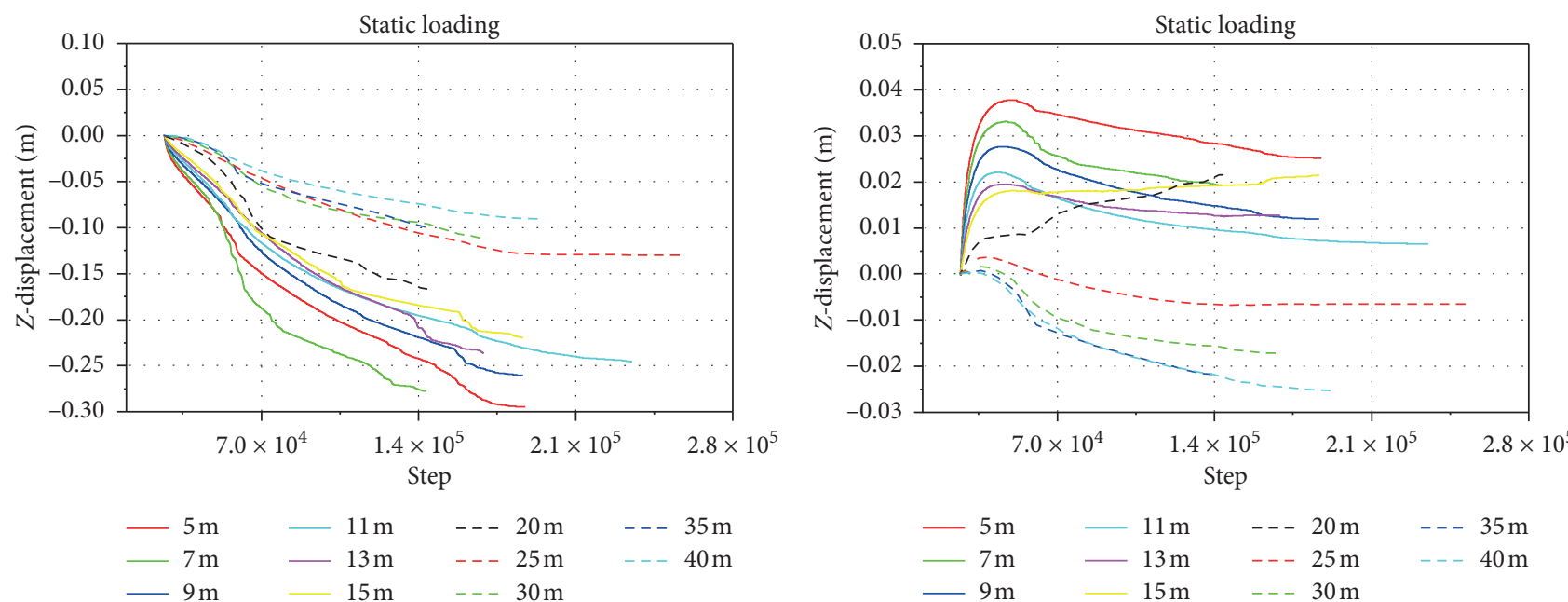

(a)
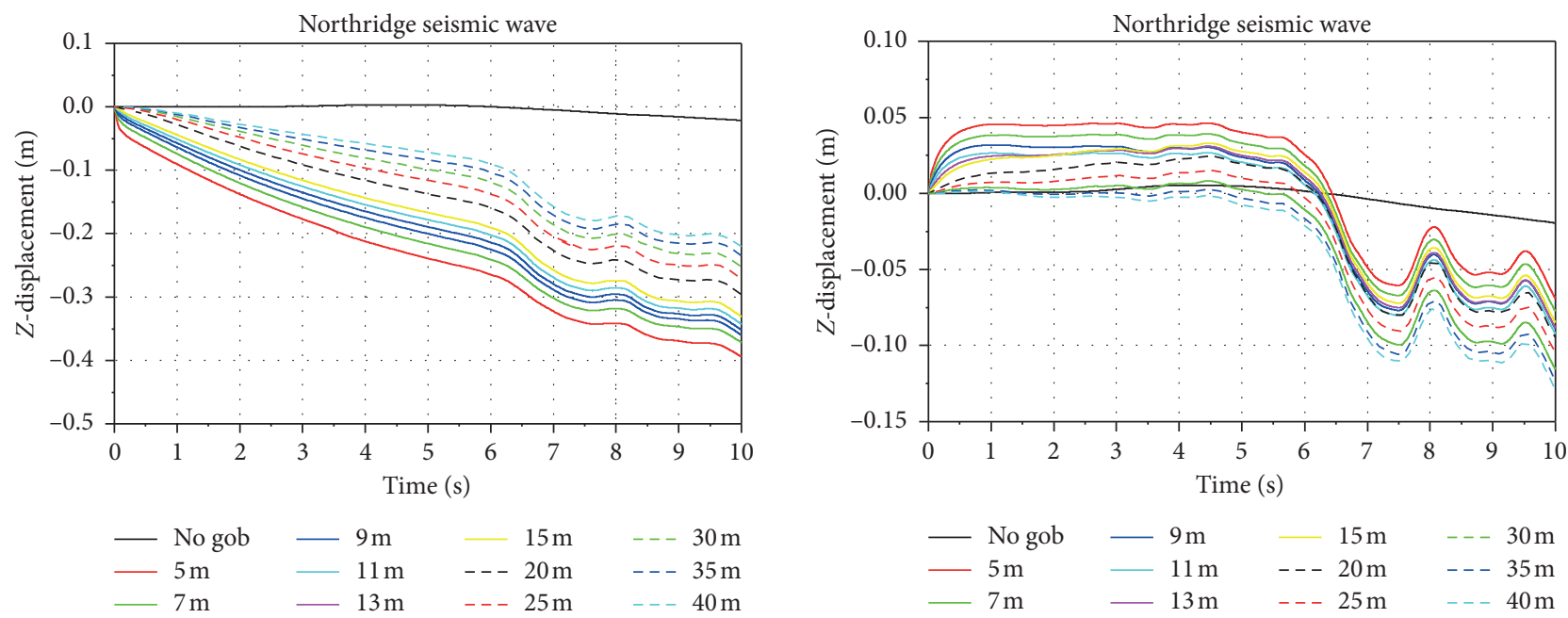

(c)
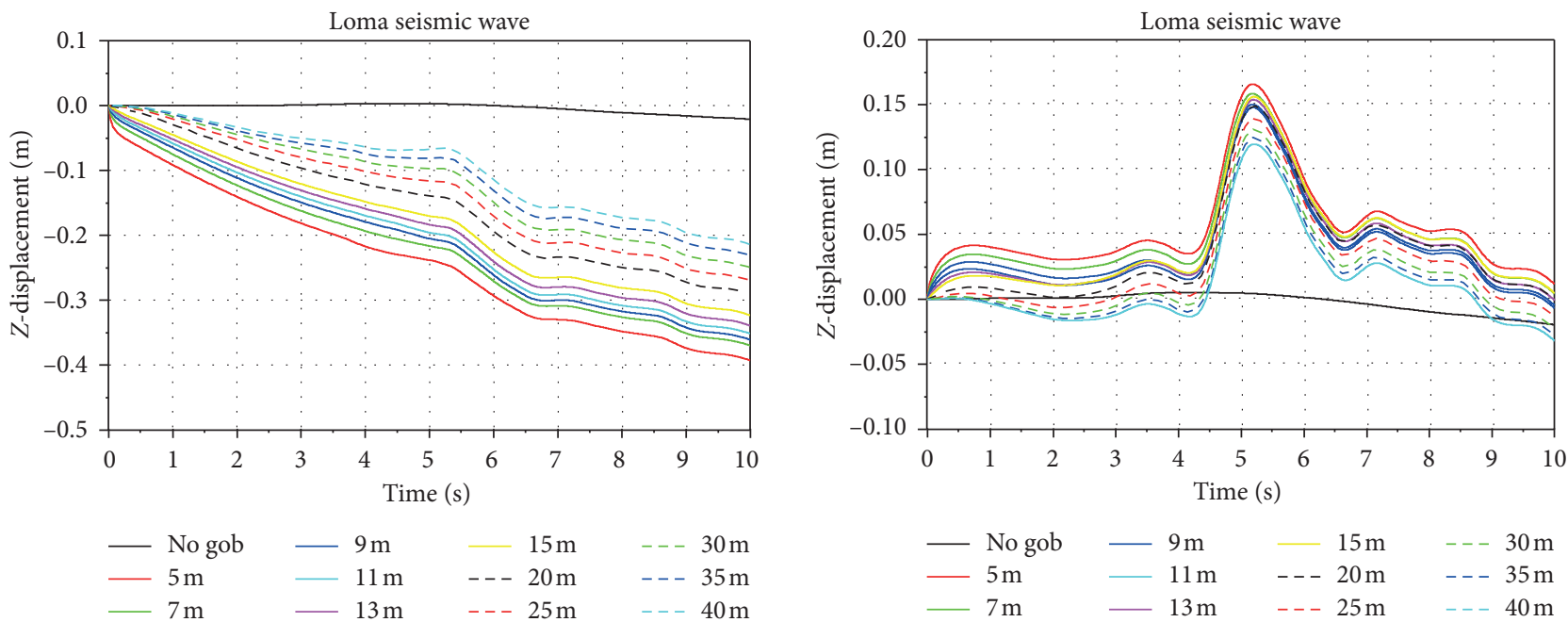

(e)

Figure 9: Continued. 


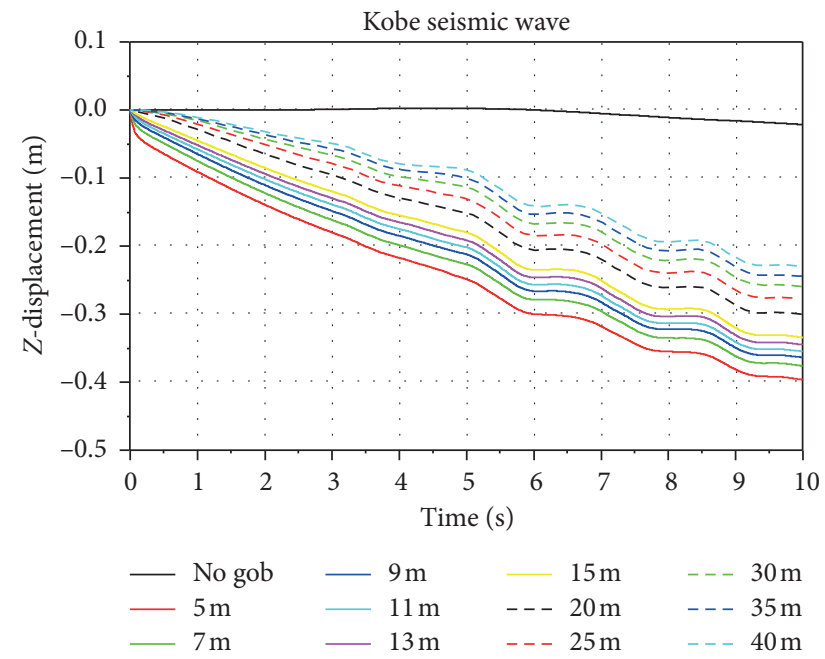

(g)

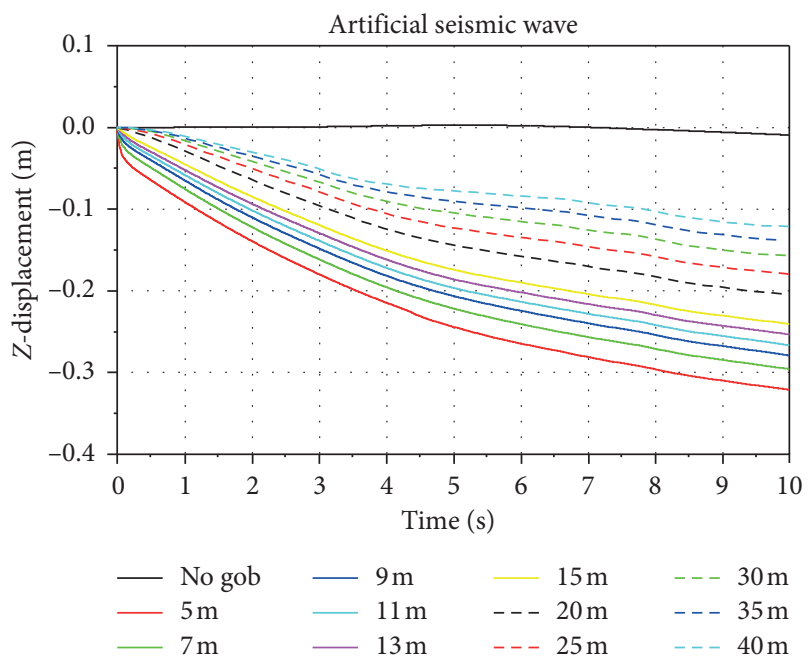

(i)

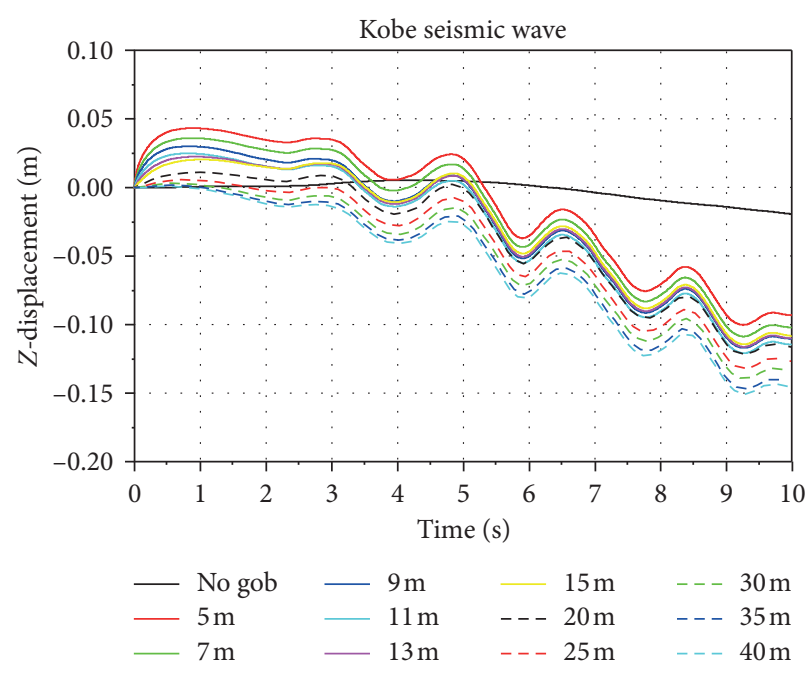

(h)

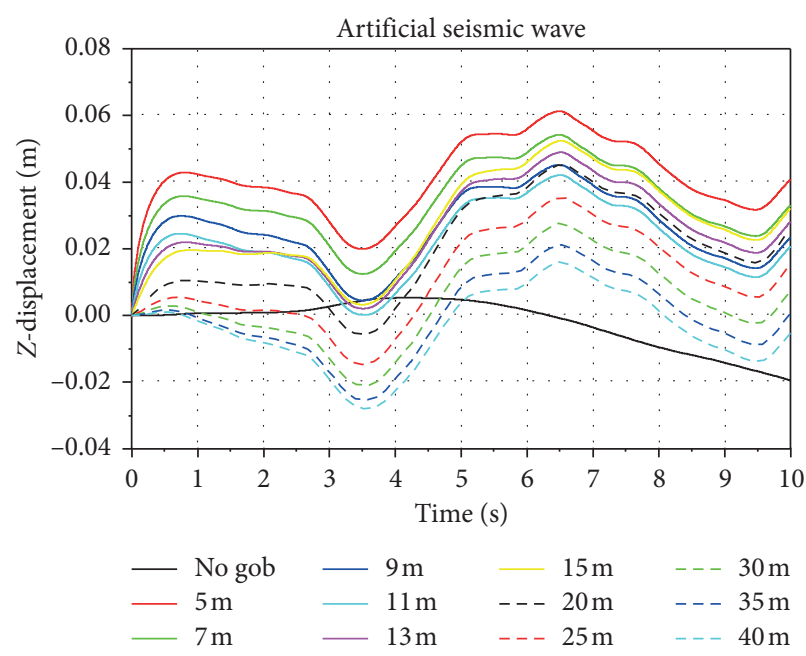

(j)

Figure 9: Vertical displacement curve of monitoring points: (a, c, e, g, i) vertical displacement of monitoring point 3, m, and (b, d, f, h, j) vertical displacement of monitoring point $7, \mathrm{~m}$.

the width of the coal pillar is increased. The symbol here is opposite to the axis direction when the model is built; thus, this stress distribution is negative. In the range of 9-20 m, the high-stress areas formed on the sides of the goafs and the side of the roadway gradually converge, and this condition forms a stress core with a high value, which is extremely detrimental to the stability of the coal pillars, especially in the process of mining. No convergence occurs between the stress on the side of the roadway under the coal pillars with width of 20-40 $\mathrm{m}$ and the stress on the sides of the goafs due to the distance, which is beneficial to the stability of the coal pillars. However, the wide coal pillars reduce the rate of resource extraction especially for the scarce types of coal to improve the recovery rate. The use of narrow coal pillars entry protection is relatively economical.

Under the action of the Northridge seismic wave, the stress value of the whole model is lower than that of the static load. This condition indicates that the stress concentration in the coal pillars is not evident under the dynamic action. However, the stress concentration area of the whole coal pillars is still distributed on the solid coal side of the roadway and inside the coal pillars but may gradually spread to the top and the bottom. The high value of local stress is at most around $20 \mathrm{MPa}$, which is relatively safe for the stability of coal pillars. However, as mentioned earlier, the displacement of the coal pillar side of the roadway increases as the earthquake continues, and this condition may cause the risk of instability for coal pillars that are subject to continuous or frequent movement. Therefore, the narrow coal pillars cannot ensure the safety of the coal pillars and roadway under the dynamic action and should be increased to $20 \mathrm{~m}$ or more to ensure safety.

Figure 12 shows the vertical stress distribution within the coal pillars in the adjacent goafs under 5 and $20 \mathrm{~m}$ wide coal pillars and the action of the Loma seismic wave. The distances of $a, b, c$, and $d$ to the goafs are $0.5,1.5,2.5$, and $3.5 \mathrm{~m}$, 

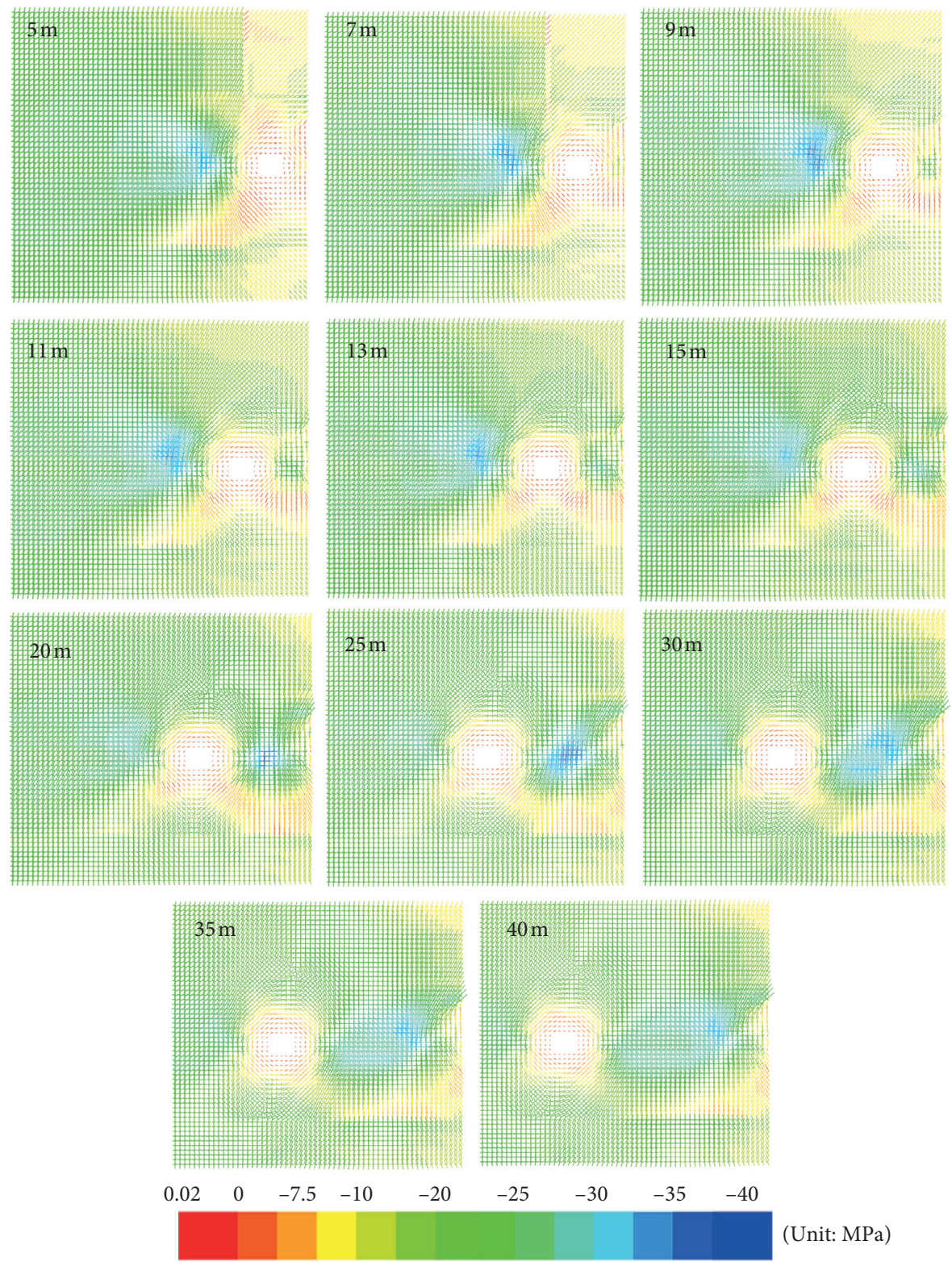

FIGURE 10: Cloud diagram of the maximum principal stress tensor of different coal pillar widths under the static load.

respectively. As shown in Figure 12, the vertical stress is higher than the vertical stress under $5 \mathrm{~m}$ wide coal pillars and is roughly distributed in the range of $-25 \mathrm{MPa}$ to $-40 \mathrm{MPa}$. Under the $5 \mathrm{~m}$ wide coal pillar, the vertical stress in the coal pillars ranges from $10 \mathrm{MPa}$ to $-15 \mathrm{MPa}$. Given the plastic damage to the $5 \mathrm{~m}$ wide coal pillar, the overlying strata and roof can no longer be supported, and this condition shifts the stress. Figure 12 shows that the vertical stresses in the 5 and $20 \mathrm{~m}$ wide coal pillars are unevenly distributed in areas closer to the goaf. Evident unevenness is observed when the coal pillar is close to the goaf. With the increased distance from the goaf, the stress gradually becomes uniform, which indicates that the loose medium of the goaf causes uneven stress of the coal pillar in the close range from the goaf, and the influence of the position of the distance is gradually reduced.

\section{Distribution Analysis of the Plastic Zone}

Figures 13 and 14 show the distribution of plastic regions under the static load and Kobe seismic waves, respectively. The blue area represents the area where no plastic damage has occurred, the red area represents the area where shear damage has occurred, and the purple area represents the area where stretching and shearing damages have occurred. As shown in Figures 13 and 14, the plastic area under the static load occurs around the roadway, and the plastic area under dynamic action expands along the coal seam in the horizontal direction with a striped distribution.

Under the static load, the area of the plastic zone in the range of $5-15 \mathrm{~m}$ is insignificantly reduced, but the plastic area within the coal pillars always runs through the entire coal pillars with the widening of the coal pillars. Therefore, 

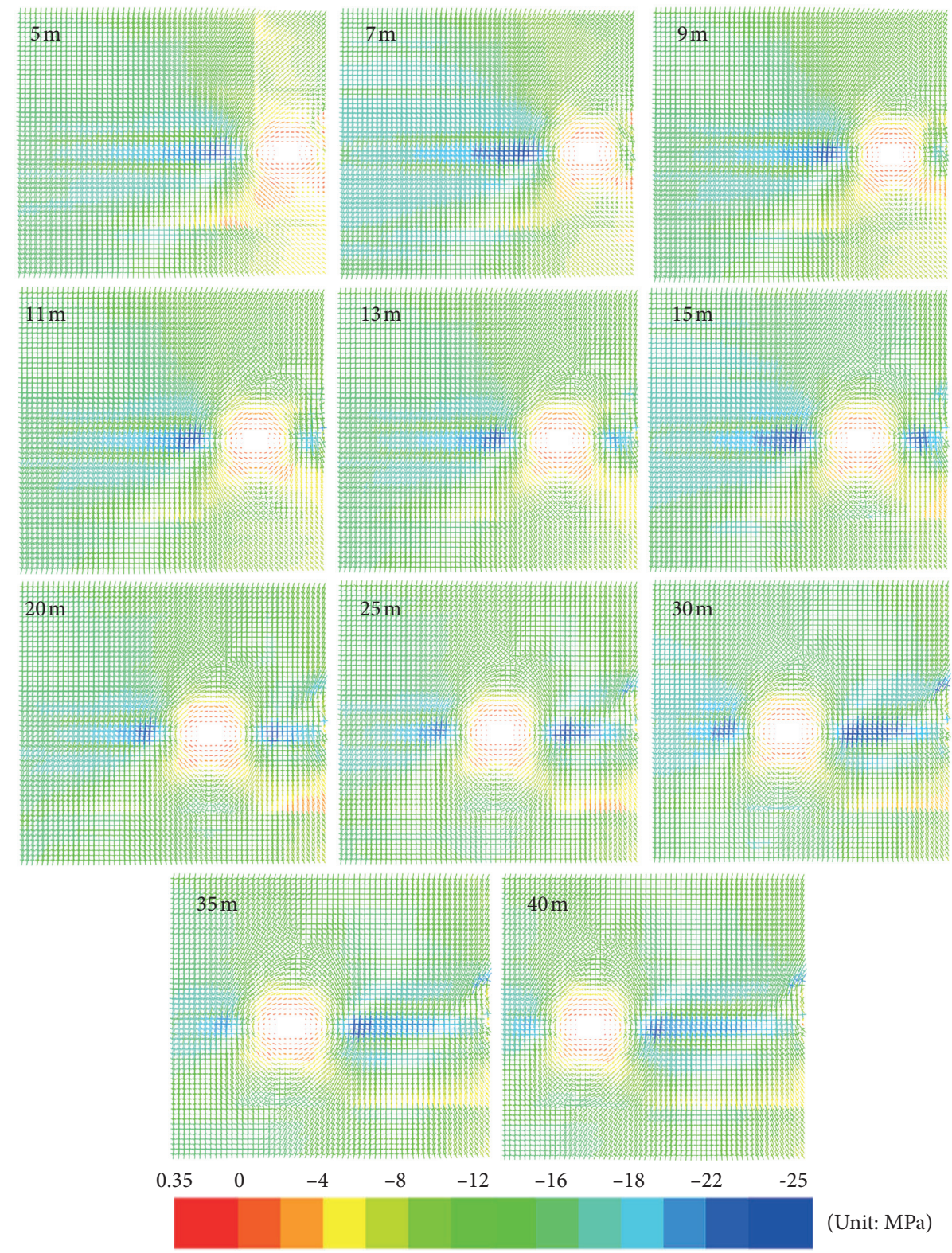

(Unit: MPa)

FIgURE 11: Cloud diagram of the maximum principal stress tensor of different coal pillar widths under the Northridge seismic wave.

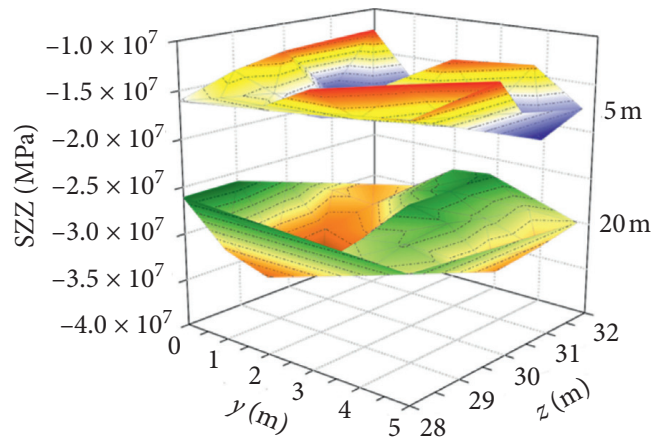

(a)

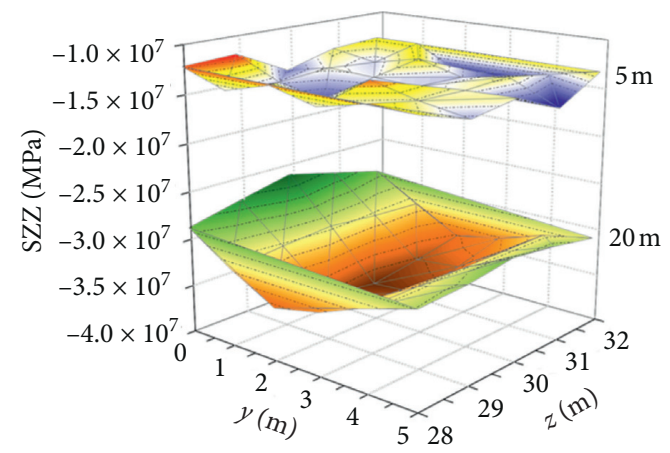

(b)

Figure 12: Continued. 


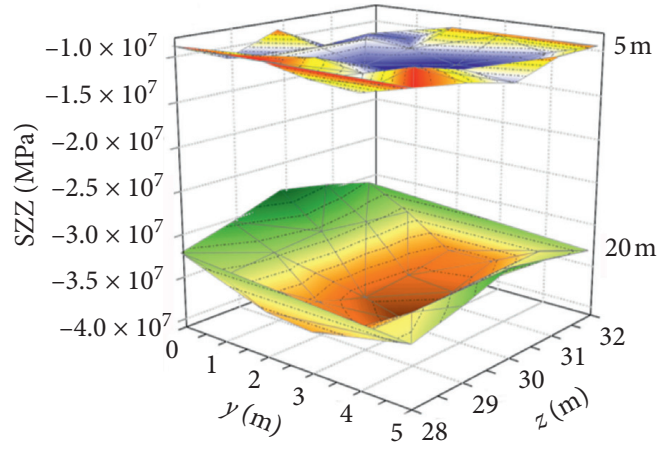

(c)

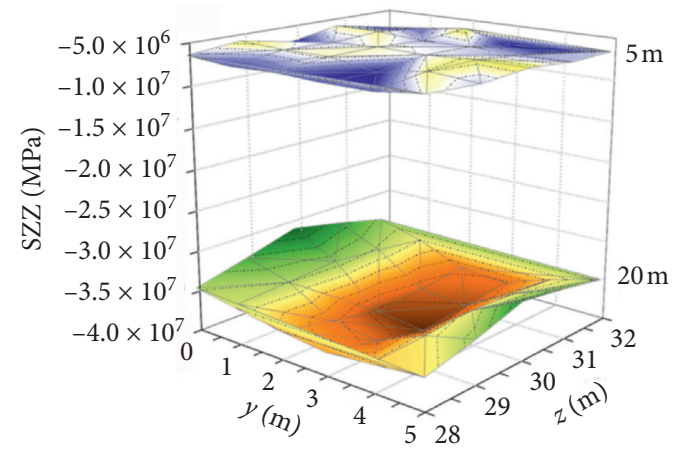

(d)

FIgURE 12: Cloud diagram of the comparison of the vertical stress under 5 and $20 \mathrm{~m}$ wide coal pillar under the Loma seismic wave: in (a), (b), (c), and (d), vertical section distances to the goafs are $0.5,1.5,2.5$, and $3.5 \mathrm{~m}$, respectively.
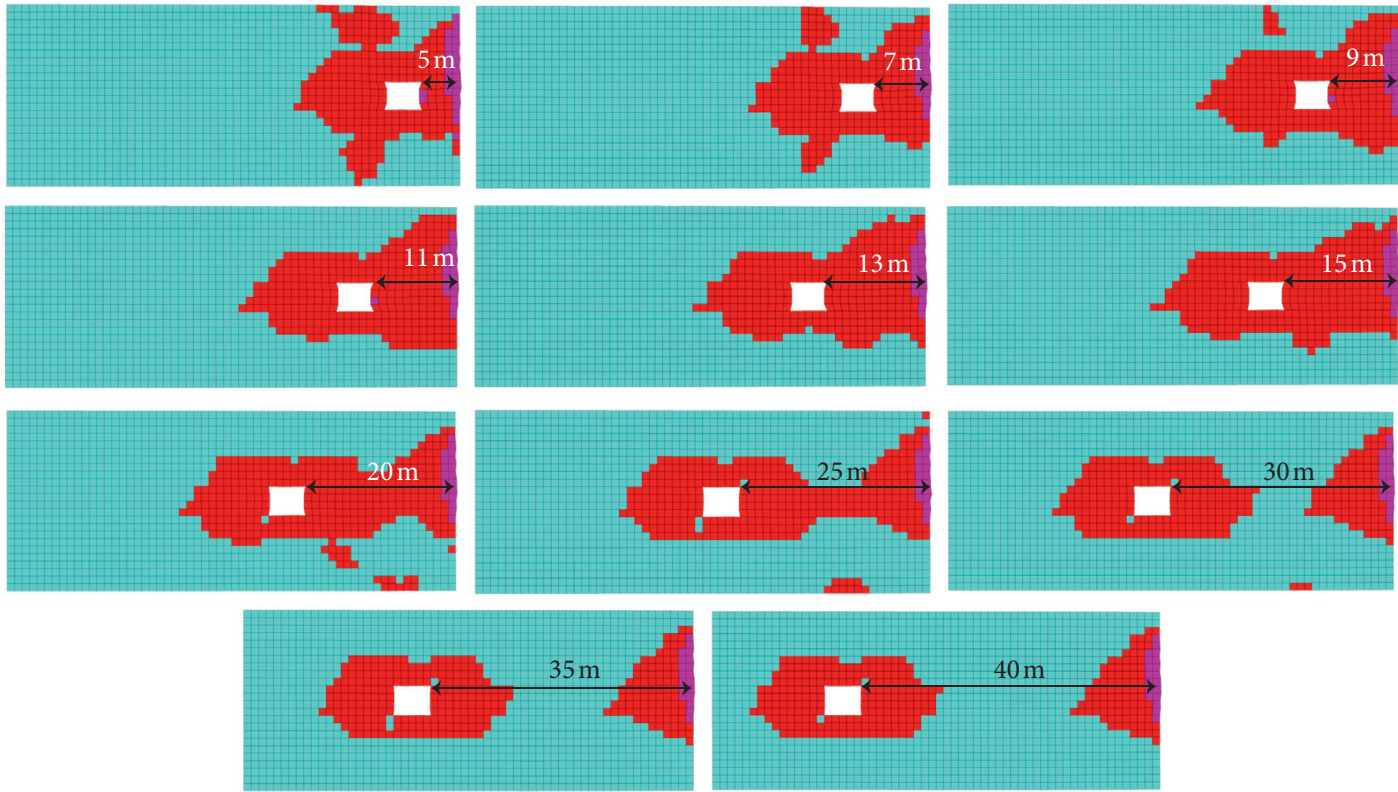

No failure

Shear failure

Shear + tensile failure

FIGURE 13: Distribution of roadways and coal pillar plastic zone under the static load.

increasing the width of the coal column from $5 \mathrm{~m}$ to $15 \mathrm{~m}$ does not reduce the plastic damage, which is affected by the goaf. When the width of the coal pillar increases to $20 \mathrm{~m}$, the plastic area within the coal pillar is gradually reduced. For the coal mining, the coal pillar without plastic damage has higher carrying capacity than that with plastic damage and is relatively safe for coal mining. Wide coal pillars are often used for coal mining in the past.

The distribution of plastic areas under the influence of seismic waves in a single roadway not affected by the goaf is shown in the no gob of Figure 14. A certain range of shear plastic failure areas occur around the roadway, the range of which increases with the continuous occurrence of the earthquake. The distribution of plastic regions under the action of Kobe seismic waves is different from that of static load. With increased width of the coal pillar, the length of the plastic area does not decrease significantly. This finding implies that the plastic area expands with the low strength of the coal seam with the continuous seismic movement, whereas the coal column, which plays a supporting role, completely causes plastic damage. As mentioned earlier, the amount of deformation of the coal pillar where plastic damage occurs gradually increases as the earthquake continues. After the plastic damage occurs, the carrying capacity of the coal pillar is greatly reduced. At this point, the risk can only be reduced by increasing the width of the coal pillar or by strengthening the support of the coal pillar. The coal pillars under the frequent or the continuous 

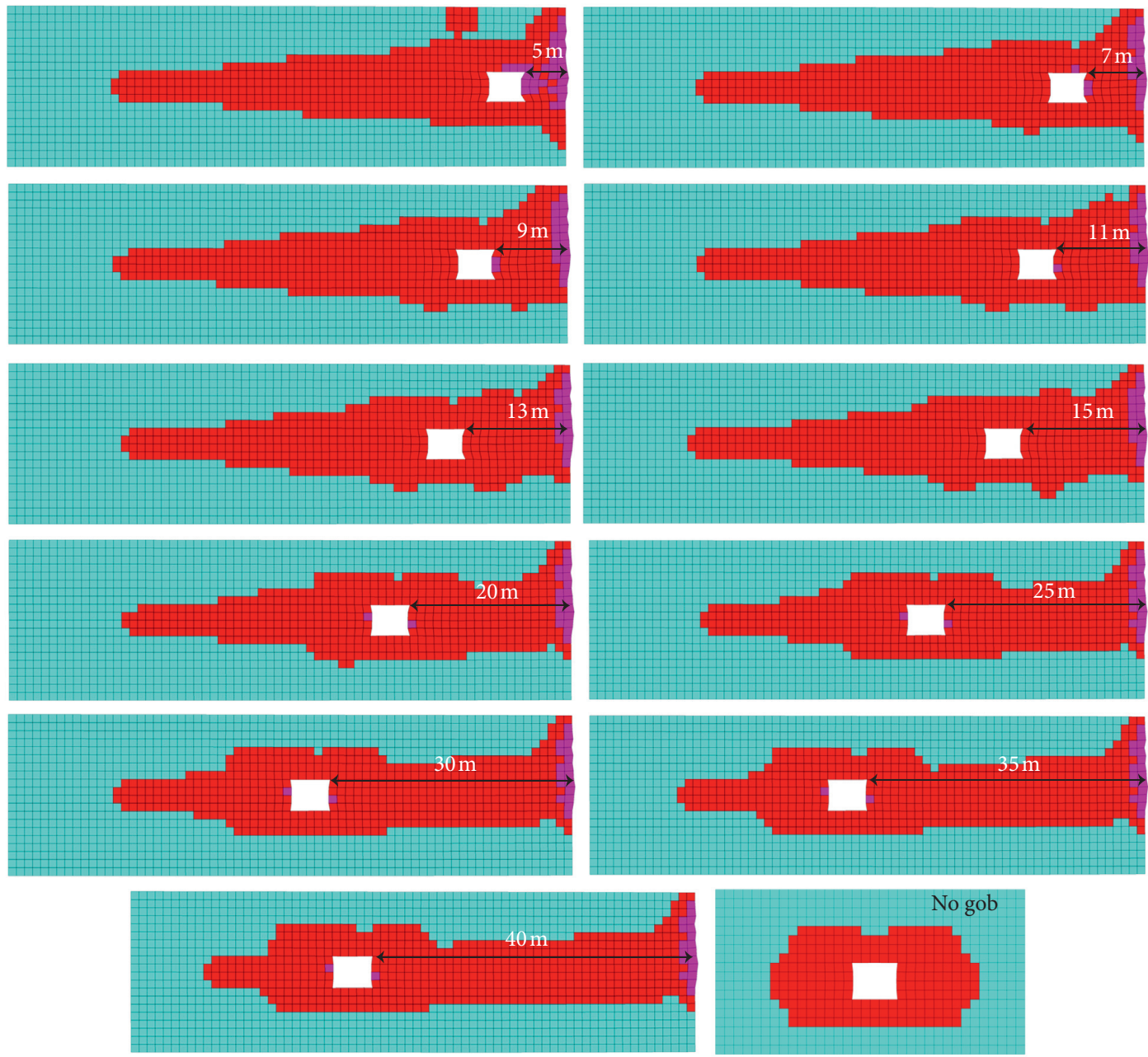

No failure

Shear failure

Shear + tensile failure

Figure 14: Distribution of roadways and the coal pillar plastic zone under the Kobe seismic wave.

dynamic action have a large area of plastic damage. At this time, the width of the coal pillar should be increased to ensure safety.

\section{Conclusions}

The seismic response analysis of coal pillars and roadways of adjacent goafs was conducted using the numerical method by utilizing the return airway of the 7435 working face in the Kongzhuang Coal Mine as a case study. The goaf was established using a different bulk model from the past, which was more in line with the actual situation of coal mining. Under the FEM and the DEM, the seismic response analysis was performed on coal pillars and roadways under different coal pillar widths and four seismic waves. This numerical method can be used to determine the width of coal pillars in gob-side entry driving.

The results show that the effect of the bulk medium on the surrounding continuous medium was simply verified because of the effect of the dispersal contact stress, which led to the nonuniform distribution of stress with the continuous medium part of the bulk body and was confirmed in subsequent calculations. For coal pillars and roadways in adjacent goafs that were subject to frequent or sustained dynamic load, a great difference between the static load and a single roadway not affected by the goaf was observed. The deformation of coal pillars and roadways increased with the continuous dynamic load. Narrow coal pillars showed this characteristic, and this trend was reflected in the coal pillar deformation. The stress concentration in the coal pillar tended to weaken compared with the static load with the continuous earthquake motion, and the high-stress area gradually spread to the top and the floors of the coal pillar. The range of plastic areas in roadways and coal pillars gradually expanded along the direction of weak coal seams as the earthquake motion continued. For the coal pillars and roadways in the adjacent goafs that were subject to frequent or sustained dynamic loads, the width of the coal pillar was increased to ensure the stability of roadways and coal pillars, and the width of the coal pillar should be calculated and determined according to the geological background and site. 


\section{Data Availability}

All data, models, or code generated or used during the study are available in a repository or online in accordance with funder data retention policies.

\section{Conflicts of Interest}

The authors declare that they have no conflicts of interest.

\section{Acknowledgments}

This research was funded by the National Natural Science Foundation of China (nos. 11872300 and 11572244), Natural Science Foundation of Shaanxi Province of China (2021JQ463 and 2021JZ-47), and the Youth Innovation Team of Shaanxi Universities.

\section{References}

[1] S. Tanimura, K. Mimura, T. Nonaka, and W. Zhu, "Dynamic failure of structures due to the great Hanshin-Awaji earthquake," International Journal of Impact Engineering, vol. 24, no. 6-7, pp. 583-596, 2000.

[2] W. L. Wang, T. T. Wang, J. J. Su, C. H. Lin, C. R. Seng, and T. H. Huang, "Assessment of damage in mountain tunnels due to the Taiwan Chi-Chi earthquake," Tunnelling And Underground Space Technology, vol. 16, no. 3, pp. 133-150, 2001.

[3] Z. Wang, B. Gao, Y. Jiang, and S. Yuan, "Investigation and assessment on mountain tunnels and geotechnical damage after the Wenchuan earthquake," Science in China Series E: Technological Sciences, vol. 52, no. 2, pp. 546-558, 2009.

[4] S. M. Hsiung, W. Blake, A. H. Chowdhury, and T. J. Williams, "Effects of mining-induced seismic events on a deep underground mine," Pure and Applied Geophysics, vol. 139, no. 3, pp. 741-762, 1992.

[5] W. Kuhnt, P. Knoll, H. Grosser, and H.-J. Behrens, "Seismological models for mining-induced seismic events," Seismicity in Mines, vol. 129, no. 3, pp. 513-521, 1989.

[6] J. A. Vallejos and S. D. McKinnon, "Correlations between mining and seismicity for re-entry protocol development," International Journal of Rock Mechanics and Mining Sciences, vol. 48, no. 4, pp. 616-625, 2011.

[7] W. Cai, L. Dou, G. Si, and Y. Hu, "Fault-induced coal burst mechanism under mining-induced static and dynamic stresses," Engineering, 2020.

[8] S. J. Gibowicz, "Seismicity induced by mining: recent research," Advances in Geophysics, vol. 51, pp. 1-53, 2009.

[9] J.-Q. Kang, J.-B. Zhu, and J. Zhao, "A review of mechanisms of induced earthquakes: from a view of rock mechanics," Geomechanics and Geophysics for Geo-Energy and Geo-Resources, vol. 5, no. 2, pp. 171-196, 2019.

[10] Coal Mines Planning and Design Institute, "The damage Kailuan coal mine roadway project in Tangshan earthquake," Seismic Engineering and Engineering Vibration, no. 1, pp. 67-76, 1982.

[11] Y. Zeng, "Viscoelastic stress-triggering of the 1999 hector mine earthquake by the 1992 landers earthquake," Geophysical Research Letters, vol. 28, no. 15, pp. 3007-3010, 2001.

[12] T. Li, M. F. Cai, and M. Cai, "A review of mining-induced seismicity in China," International Journal of Rock Mechanics and Mining Sciences, vol. 44, no. 8, pp. 1149-1171, 2007.
[13] W. Yu, B. Pan, F. Zhang, S. Yao, and F. Liu, "Deformation characteristics and determination of optimum supporting time of alteration rock mass in deep mine," KSCE Journal of Civil Engineering, vol. 23, no. 11, pp. 4921-4932, 2019.

[14] Y. Li, Y. Yang, and B. Jiang, "Prediction of coal and gas outbursts by a novel model based on multisource information fusion," Energy Exploration \& Exploitation, vol. 38, no. 5, pp. 1320-1348, 2020.

[15] P. Konicek and P. Waclawik, "Stress changes and seismicity monitoring of hard coal longwall mining in high rockburst risk areas," Tunnelling and Underground Space Technology, vol. 81, pp. 237-251, 2018.

[16] M. V. Kurlenya, M. N. Tsupov, and A. V. Savchenko, "Influence of the bachatsky earthquake on methane emission in roadways in coal mines," Journal of Mining Science, vol. 55, no. 5, pp. 695-700, 2019.

[17] P. Konicek and J. Schreiber, "Heavy rockbursts due to longwall mining near protective pillars: a case study," International Journal of Mining Science and Technology, vol. 28, no. 5, pp. 799-805, 2018.

[18] C. Srinivasan, S. K. Arora, and R. K. Yaji, "Use of mining and seismological parameters as premonitors of rockbursts," International Journal of Rock Mechanics and Mining Sciences, vol. 34, no. 6, pp. 1001-1008, 1997.

[19] T.-H. Ma, C.-A. Tang, S.-B. Tang et al., "Rockburst mechanism and prediction based on microseismic monitoring," International Journal of Rock Mechanics and Mining Sciences, vol. 110, pp. 177-188, 2018.

[20] X.-S. He, S.-Y. Li, K. Pan et al., "Mining seismicity, gas outburst and the significance of their relationship in the study of physics of earthquake source," Acta Seismologica Sinica, vol. 20, no. 3, pp. 332-347, 2007.

[21] J. Wang, J. Jiang, G. Li, and H. Hu, "Exploration and numerical analysis of failure characteristic of coal pillar under great mining height longwall influence," Geotechnical and Geological Engineering, vol. 34, no. 2, pp. 689-702, 2016.

[22] X. Li, Y. Zhao, W. He, L. Li, and F. He, "Study on coal pillar width and surrounding rock control of gob-side entry in extra-thick coal seam," Geotechnical and Geological Engineering, vol. 38, no. 6, pp. 6855-6868, 2020.

[23] Y. Zhang, Z. Wan, F. Li et al., "Stability of coal pillar in gobside entry driving under unstable overlying strata and its coupling support control technique," International Journal of Mining Science and Technology, vol. 23, no. 2, pp. 193-199, 2013.

[24] J. Yang, S. Cao, and X. Li, "Failure laws of narrow pillar and asymmetric control technique of gob-side entry driving in island coal face," International Journal of Mining Science and Technology, vol. 23, no. 2, pp. 267-272, 2013.

[25] N. Zhang, X. Li, and J. Zhou, "Supporting of gob-side entries driving head-on adjacent advancing coal face with a reserved narrow pillar," Mining Science and Technology, CRC Press, Boca Raton, FL, USA, 2004.

[26] Y. Xu, H. Li, G. Guo, and X. Liu, "Stability analysis of hyperbolic coal pillars with peeling and high temperature effects," Energy Exploration \& Exploitation, vol. 38, no. 5, pp. 1574-1588, 2020.

[27] J. Liu, C. Liu, and X. Li, "Determination of fracture location of double-sided directional fracturing pressure relief for hard roof of large upper goaf-side coal pillars," Energy Exploration \& Exploitation, vol. 38, no. 1, pp. 111-136, 2020.

[28] G.-L. Feng, X.-T. Feng, B.-R. Chen, Y.-X. Xiao, and Y. Yu, “A microseismic method for dynamic warning of rockburst 
development processes in tunnels," Rock Mechanics and Rock Engineering, vol. 48, no. 5, pp. 2061-2076, 2015.

[29] G.-I. Feng, B.-R. Chen, Q. Jiang, Y.-X. Xiao, W.-J. Niu, and P.-X. Li, "Excavation-induced microseismicity and rockburst occurrence: similarities and differences between deep parallel tunnels with alternating soft-hard strata," Journal of Central South University, vol. 28, no. 2, pp. 582-594, 2021.

[30] G.-L. Feng, S.-T. Feng, Y.-X. Xiao et al., "Characteristic microseismicity during the development process of intermittent rockburst in a deep railway tunnel," International Journal of Rock Mechanics And Mining Sciences, vol. 124, 2019.

[31] X. Li and Y. Chai, "Determination of pillar width to improve mining safety in a deep burst-prone coal mine," Safety Science, vol. 113, pp. 244-256, 2019.

[32] Y. Zhao, H. Wang, S. Liu, Z. Mu, and Z. Lu, "Dynamic failure risk of coal pillar formed by irregular shape longwall face: a case study," International Journal of Mining Science and Technology, vol. 28, no. 5, pp. 775-781, 2018.

[33] S.-L. Wang, S.-P. Hao, Y. Chen, J.-B. Bai, X.-Y. Wang, and $\mathrm{Y}$. $\mathrm{Xu}$, "Numerical investigation of coal pillar failure under simultaneous static and dynamic loading," International Journal of Rock Mechanics and Mining Sciences, vol. 84, pp. 59-68, 2016.

[34] T. Wang, C. Yang, X. Yan et al., "Dynamic response of underground gas storage salt cavern under seismic loads," Tunnelling and Underground Space Technology, vol. 43, pp. 241-252, 2014.

[35] W. Yu and K. Li, "Deformation mechanism and control technology of surrounding rock in the deep-buried large-span chamber," Geofluids, vol. 2020, Article ID 8881319, 22 pages, 2020.

[36] W. Yu, W. Yu, G. Wu, B. An, and P. Wang, "Experimental study on the brittle-ductile response of a heterogeneous soft coal rock mass under multifactor coupling," Geofluids, vol. 2019, Article ID 5316149, 15 pages, 2019.

[37] T. Han, J. Shi, and X. Cao, "Fracturing and damage to sandstone under coupling effects of chemical corrosion and freeze-thaw cycles," Rock Mechanics and Rock Engineering, vol. 49, no. 11, pp. 4245-4255, 2016.

[38] B. Xia, J. Jia, B. Yu, X. Zhang, and X. Li, "Coupling effects of coal pillars of thick coal seams in large-space stopes and hard stratum on mine pressure," International Journal of Mining Science and Technology, vol. 27, no. 6, pp. 965-972, 2017.

[39] Q. Bai, S. Tu, F. Wang, and C. Zhang, "Field and numerical investigations of gateroad system failure induced by hard roofs in a longwall top coal caving face," International Journal of Coal Geology, vol. 173, pp. 176-199, 2017.

[40] L. Jiang, P. Zhang, L. Chen et al., "Numerical approach for goaf-side entry layout and yield pillar design in fractured ground conditions," Rock Mechanics and Rock Engineering, vol. 50, no. 11, pp. 3049-3071, 2017.

[41] Q. Sun and D. Dias, "Significance of Rayleigh damping in nonlinear numerical seismic analysis of tunnels," Soil Dynamics and Earthquake Engineering, vol. 115, pp. 489-494, 2018.

[42] J. M. Mayoral and F. A. Flores, "Effects of soil cracking on the seismic response of soil-structure systems," Soil Dynamics and Earthquake Engineering, vol. 30, no. 6, pp. 509-523, 2010.

[43] J. M. Mayoral, S. Tepalcapa, A. Roman-de la Sancha, C. S. El Mohtar, and R. Rivas, "Ground subsidence and its implication on building seismic performance," Soil Dynamics and Earthquake Engineering, vol. 126, Article ID 105766, 2019.
[44] M. Wang, "Simulation of compression test on gangue by PFC3D," Chinese Journal of Rock Mechanics and Engineering, vol. 32, pp. 1351-1357, 2013.

[45] M. Bai, F. S. Kendorski, and D. J. Van Roosendaal, Chinese and North American High-Extraction Underground Coal Mining Strata Behavior and Water Protection Experience and Guidelines, West Virginia University, Morgantown, WV, USA, 1995.

[46] Pacific Earthquake Engineering Research Center, http://peer. berkeley.edu/peer_ground_motion_database/.

[47] Earthquake Software for Signal Processing of Strong-Motion Data, http://www.seismosoft.com. 